\title{
Dead time effect on the Brewer measurements: correction and estimated uncertainties
}

\author{
Ilias Fountoulakis ${ }^{1}$, Alberto Redondas ${ }^{2}$, Alkiviadis F. Bais ${ }^{1}$, Juan José Rodriguez-Franco ${ }^{2}$, Konstantinos Fragkos ${ }^{1}$, \\ and Alexander Cede Cen $^{3,4}$ \\ ${ }^{1}$ Aristotle University of Thessaloniki, Laboratory of Atmospheric Physics, Thessaloniki, Greece \\ ${ }^{2}$ Agencia Estatal de Meteorología, Izaña Atmospheric Research Center, Tenerife, Canary Islands, Spain \\ ${ }^{3}$ NASA/Goddard Space Flight Center, Greenbelt, MD, USA \\ ${ }^{4}$ LuftBlick, Kreith, Austria \\ Correspondence to: Ilias Fountoulakis (iliasnf@auth.gr)
}

Received: 22 October 2015 - Published in Atmos. Meas. Tech. Discuss.: 3 December 2015

Revised: 16 April 2016 - Accepted: 18 April 2016 - Published: 26 April 2016

\begin{abstract}
Brewer spectrophotometers are widely used instruments which perform spectral measurements of the direct, the scattered and the global solar UV irradiance. By processing these measurements a variety of secondary products can be derived such as the total columns of ozone (TOC), sulfur dioxide and nitrogen dioxide and aerosol optical properties. Estimating and limiting the uncertainties of the final products is of critical importance. High-quality data have a lot of applications and can provide accurate estimations of trends.

The dead time is specific for each instrument and improper correction of the raw data for its effect may lead to important errors in the final products. The dead time value may change with time and, with the currently used methodology, it cannot always be determined accurately. For specific cases, such as for low ozone slant columns and high intensities of the direct solar irradiance, the error in the retrieved TOC, due to a $10 \mathrm{~ns}$ change in the dead time from its value in use, is found to be up to $5 \%$. The error in the calculation of UV irradiance can be as high as $12 \%$ near the maximum operational limit of light intensities. While in the existing documentation it is indicated that the dead time effects are important when the error in the used value is greater than $2 \mathrm{~ns}$, we found that for single-monochromator Brewers a 2 ns error in the dead time may lead to errors above the limit of $1 \%$ in the calculation of TOC; thus the tolerance limit should be lowered. A new routine for the determination of the dead time from direct solar irradiance measurements has been created and tested and a validation of the operational algorithm has been performed.
\end{abstract}

Additionally, new methods for the estimation and the validation of the dead time have been developed and are analytically described. Therefore, the present study, in addition to highlighting the importance of the dead time for the processing of Brewer data sets, also provides useful information for their quality control and re-evaluation.

\section{Introduction}

In the beginning of the $1980 \mathrm{~s}$, the increased concern for the stratospheric ozone depletion (Farman et al., 1985) and its effects on surface UV levels (Kerr and McElroy, 1993; Zerefos, 2002) stimulated the deployment of the first Brewer ozone spectrophotometers. Until 1996 Brewer instruments were manufactured by SCI-TEC Instruments Inc. in Canada. In 1996, SCI-TEC Instruments Inc. merged with Kipp and Zonen B.V.; since then the Brewer spectrophotometers are produced in Delft, the Netherlands. Nowadays, more than 200 instruments are deployed worldwide. Brewers are either single monochromators (versions MKII, MKIV and MKV) or double monochromators (version MKIII) and may be equipped with multiple-board or single-board electronics. Although of the same make, the characteristics of individual instruments may differ significantly. The Brewer network provides a variety of products such as the total columns of ozone (TOC) (Kerr et al., 1981), $\mathrm{SO}_{2}$ (Cappellani and Bielli, 1995) and $\mathrm{NO}_{2}$ (Cede et al., 2006; Diémoz et al., 2014), the aerosol optical depth (AOD) (Bais et al., 2005; Gröbner 
and Meleti, 2004; Meleti and Cappellani, 2000) as well as global and direct irradiance spectra (Bais et al., 1993, 1996). These measurements have supported scientific research for more than 30 years, enabling the investigation of their shortand long-term variability (Glandorf et al., 2005; Weatherhead et al., 1998; Zerefos, 2002) and interactions among them and among other atmospheric constituents (Bernhard et al., 2007). Additionally, good-quality ground-based measurements are very useful for the validation of satellite products which, under specific conditions, may be highly uncertain (Fioletov et al., 2002).

The uncertainty in the TOC retrieval is estimated to about $1 \%$ (Kerr et al., 1985), while for well-maintained and properly calibrated instruments, the uncertainty of UV spectral irradiance is estimated to about 10 and $5 \%$ for the UVB and the UVA spectral regions, respectively (Bais et al., 1996). More recent studies indicated that the measurements can be largely affected by the individual characteristics of each instrument (Gröbner et al., 2006) and that proper corrections are needed in order to keep the uncertainties within the above mentioned limits or even reduce them further (Garane et al., 2006; Karppinen et al., 2014; Lakkala et al., 2008).

However, there are uncertainties related to constructional, technical or operational characteristics of the instruments which are not adequately investigated and documented, and it is debatable whether the applied relevant corrections are optimal. The dead time of the photon counting systems used in the Brewers is one of these characteristics. The dead time is a measure of how long a photon counting circuit is unable to detect a second photon after a first photon has been detected (SCI-TEC Instruments Inc., 1999). The probability that a photon reaches the counting system within this "dead" time interval increases with the rate of the overall incoming photons (i.e., with intensity of radiation). Thus, the recorded signals have to be properly corrected to compensate the nonlinear response of the system due to the effect of the dead time. For the correction a dead time constant (DT) is used, which is initially determined by the manufacturer, but during regular operation it is calculated and recorded on daily basis by the Brewer operating software. Although the theoretical description of the dead time effect and the methods to determine the DT and apply corrections to the data of Brewer spectrophotometers have been adequately documented (Fountoulakis and Bais, 2014; Kerr, 2010; Kiedron, 2007; Kimlin et al., 2005; Redondas and Rodriguez-Franco, 2012; Rodriguez-Franco et al., 2014; Savastiouk, 2005; SCITEC Instruments Inc., 1999), there is little information regarding the associated uncertainties. Additionally, it is still not clear whether the currently used algorithm in Brewers is the most appropriate (Redondas et al., 2012). The present study aims at filling this gap in knowledge and effectively contributing to the reduction of the uncertainties of the products derived from Brewer spectrophotometers.

The objectives of this study have been addressed both experimentally and theoretically. Data from five different
Brewers were processed and analyzed, specifically, from the double-monochromator (type MKIII) Brewers with serial numbers 086 (B086), 157 (B157), 183 (B183) and 185 (B185) and from the single-monochromator (type MKII) Brewer with serial number 005 (B005). B005 and B086 operate at the Laboratory of Atmospheric Physics, Aristotle University of Thessaloniki, Greece $\left(40.634^{\circ} \mathrm{N}, 22.956^{\circ} \mathrm{E}\right.$; $60 \mathrm{~m}$ a.s.l.). The Brewer spectrophotometers B157, B183 and B185 form the RBCCE triad and are installed at the Izaña Atmospheric Research Center $\left(28.309^{\circ} \mathrm{N}, 16.499^{\circ} \mathrm{N}\right.$; $2373 \mathrm{~m}$ a.s.1.). The same instruments were used in the closure experiments conducted for this study.

\section{Dead time: calculation and correction of signal}

\subsection{The radiation detection system}

The Brewer spectrophotometers use a photomultiplier tube (PMT) and a photon counting circuit for the detection and counting of the photons passing through the exit slit of the monochromator. A fraction of the photons that reach the PMT generate photon pulses, according to the quantum efficiency of the PMT (Haus, 2010), and are recorded as counts. The quantum efficiency is a function of wavelength and is taken implicitly into account during the calibration. Low voltage pulses, which are more likely electronic noise and not radiation-induced signal, are filtered out using a voltage discriminator usually set to $\sim 30 \mathrm{mV}$ (Kerr, 2010). Thus, the recorded signal is the sum of counts that have been generated from photon pulses and counts from thermal noise of the electronics that were not filtered out by the discriminator. The latter are usually referred to as "dark counts" (or dark signal) and have to be subtracted from the recorded signal. The dark signal is measured by blocking the incoming radiation as part of each sample and is stored on all data records.

The DT depends on the type and the configuration of the used PMT (Kapusta et al., 2015), and thus it is specific for each instrument. For most Brewers the DT is between 15 and $45 \mathrm{~ns}$. The probability of a photon reaching the counting system within the dead time increases with increasing signal (Kerr, 2010; Kipp \& Zonen Inc., 2008; SCI-TEC Instruments Inc., 1999); thus the effect of the dead time is more important for higher signals. During regular operation, DT is calculated by measuring and comparing different levels of radiation emitted by an internal quartz-halogen $20 \mathrm{~W}$ lamp (standard lamp). The accuracy of the determined DT depends strongly on the signal-to-noise ratio, thus on the level of the lamp's signal. A weak signal may lead to large uncertainties. Since the operation of the lamp depends on other electronic circuits in the instrument, it is not always easy to assess the effect of these factors on the calculated values of DT.

During the setup of a Brewer spectrophotometer, the high voltage of the PMT is set to a value where the slope of the intensity vs. voltage is small, so that small shifts in the high 
Table 1. Uncertainty $(1 \sigma)$ in percent of the measured signal due to photon noise for different levels of the signal and number of cycles.

\begin{tabular}{lrrrrrrrr}
\hline Counts s $^{-1}$ & 1 cycle & 2 cycles & 4 cycles & 6 cycles & 10 cycles & 20 cycles & 30 cycles & 40 cycles \\
\hline $10^{2}$ & 29.53 & 20.88 & 14.76 & 12.05 & 9.34 & 6.60 & 5.39 & 4.67 \\
$10^{3}$ & 9.33 & 6.60 & 4.67 & 3.81 & 2.95 & 2.09 & 1.70 & 1.48 \\
$10^{4}$ & 2.95 & 2.09 & 1.48 & 1.21 & 0.93 & 0.66 & 0.54 & 0.47 \\
$10^{5}$ & 0.93 & 0.66 & 0.47 & 0.38 & 0.30 & 0.21 & 0.17 & 0.15 \\
$10^{6}$ & 0.29 & 0.21 & 0.15 & 0.12 & 0.09 & 0.07 & 0.05 & 0.05 \\
\hline
\end{tabular}

voltage do not affect significantly the signal, and the signalto-noise ratio is adequately high (Kipp \& Zonen Inc., 2008). The characteristics of the PMT and the counting system may gradually change with time so that re-adjustment of the high voltage is occasionally necessary. If the high voltage is not properly adjusted the response of the instrument is no longer linear, even for low-intensity signals, and high uncertainties are induced both in the calculation of DT and the correction of the signal.

When the signal is very high (e.g., of the order of $10^{7}$ counts $^{-1}$ ) the detection system is saturated and the measurements cannot be corrected for the nonlinear response (Kapusta et al., 2015; Schätzel, 1986). Thus, during regular operation, different neutral density (ND) attenuation filters are used to control the signal to within appropriate levels. The range of the detected signals is different for different types of measurements, thus different ND filters are required. For example, during direct-Sun measurements ND filters are used

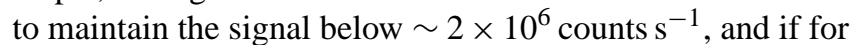

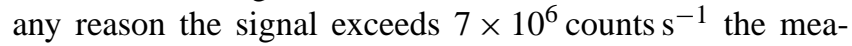
surements are automatically interrupted. For spectral scans of the global UV irradiance one specific ND filter is used in each instrument depending on its sensitivity. Although this filter keeps the signal below $10^{7}$ counts $^{-1}$, strong signals of 3-6 $\times 10^{6}$ counts $^{-1}$ are not unusual.

Measurements of very low signals have large uncertainties. For a mean rate of photons, $N$, that reach the detector, individual measurements may differ from each other due to the quantized nature of light and the independence of photon detection (Hasinoff, 2014). Since photon counting is a classic Poisson process, the Poisson (photon) noise of the measurements decreases with increasing sampling time. For $N$ photons measured within a time interval $t$, the fractional $1 \sigma$ precision is

$$
\frac{\Delta S}{S}=\frac{1}{\sqrt{N t}} \text {. }
$$

As further explained in the following, the sampling time of a measurement is defined by the rotating mask which moves (cycles) before the exit slits of the spectrometer. In each position of the mask photons from only one slit are allowed to reach the PMT, for a time interval of $0.1147 \mathrm{~s}$. Examples of the uncertainty for different signal levels and commonly used sampling times (number of cycles of the mask multiplied by
$0.1147 \mathrm{~ns}$ ) are presented in Table 1. According to Grajnar et al. (2008) the ideal operating range for the Brewer is between 1 and 2 million counts $\mathrm{s}^{-1}$.

At the exit of the monochromator there are six exit slits through which the radiation dispersed by the monochromator is directed to the PMT. When the monochromator is set for ozone observations the nominal wavelengths $\left(\lambda_{0 \rightarrow 5}\right)$ corresponding to each slit are 303.2, 306.3, 310.1, 313.5, 316.8 and $320.1 \mathrm{~nm}$, respectively. Each exit slit can be opened individually, while the others are blocked, by a rotating mask which is synchronized with the photon counting system. The six wavelengths $\left(\lambda_{0 \rightarrow 5}\right)$ correspond to positions $0,2,3,4$, 5 and 6 of the mask, respectively. There are two extra positions: 1 , when all slits are blocked and is used to determine the dark signal, and 7, when two slits corresponding to $\lambda_{2}$ and $\lambda_{4}$ are opened simultaneously, allowing the radiation of both wavelengths to reach the PMT.

The DT of a Brewer spectrophotometer is determined according to the following procedure: The radiation emitted by the standard lamp at 306.3 and $313.5 \mathrm{~nm}$ is measured sequentially by setting the rotating mask at positions 3 and 5, respectively, followed by a simultaneous measurement of both wavelengths by setting the mask to position 7 . The sequence is repeated 5 times for a high-intensity signal (using a filter with low attenuation) and 10 times for a low-intensity signal (using a filter of high attenuation) and the mean and standard deviation for each set are calculated. Measurements are considered reliable when the standard deviation is less than $2.5 \mathrm{~ns}$ for high-intensity and $20 \mathrm{~ns}$ for low-intensity signals (Grajnar et al., 2008). When the high voltage of the PMT is properly adjusted the results from the high- and the lowintensity measurements should agree to within 2 standard deviations of the former. Although the DT used for the correction of measurements should be within $2 \mathrm{~ns}$ of the value calculated daily, during the regular operation differences of 2-10 ns or even larger (e.g., in B086) are often encountered (Redondas et al., 2012; Rodriguez-Franco et al., 2014). It is not always easy to identify the causes of these differences between the calculated and the used DT or between the DT from the high- and the low-intensity measurements, and whether the DT in use should be set to a new value. Such differences may arise from problems in the optical, mechanical or electronic parts of the instrument (Grajnar et al., 2008). 


\subsection{Theoretical approach for determining the dead time constant}

Since a portion of the photons are lost due to dead time, the Brewer measurements no longer have Poisson distribution. Thus, Eq. (1) underestimates the $1 \sigma$ precision and should be replaced by the more precise Eq. (2) which takes into account the dead time effect (Kiedron, 2007):

$$
\frac{\Delta S}{S}=\frac{1}{1-\tau \cdot N_{\mathrm{I}}} \cdot \sqrt{\frac{1}{N_{\mathrm{M}} \cdot t}-\frac{\tau}{t} \cdot\left(2-\frac{\tau}{t}\right)},
$$

where $N_{\mathrm{I}}$ and $N_{\mathrm{M}}$ are the rate of photons that generate pulses (in photons $\mathrm{s}^{-1}$ ) and the detected pulses (in counts $\mathrm{s}^{-1}$ ), respectively, $t$ is the sampling time and $\tau$ is the DT. As long as $N_{\mathrm{M}}$ remains well below $\sim 3 \times 10^{6}$ counts s$^{-1}$, the results from Eqs. (1) and (2) agree to within $2 \%$, while even for count rates close to $6 \times 10^{6}$ the difference is less than $10 \%$ (Kiedron, 2007).

The algorithms that have been developed for the calculation of DT and the correction of the signal are both based on Poisson statistics. According to Schätzel (1986), the average number of pulses generated within $\tau$ is given by

$\mu=N_{\mathrm{I}} \cdot \tau$.

For a Poisson distribution the probability $P(k)$ of $k$ pulses within $\tau$ is then given by

$P(k)=\frac{1}{k !} \cdot e^{-\mu} \cdot \mu^{k}$.

The sum of probabilities for all values of $k$ ( 0 to infinity) equals unity. The probability of exactly one pulse within $\tau$ is

$P(k=1)=\frac{1}{1 !} \cdot e^{-\mu} \cdot \mu^{1}=\mu \cdot e^{-\mu}$,

while the probability for one or more pulses within $\tau$ is

$P(k \geq 1)=1-P(k=0)=1-e^{-\mu}$.

Using Eqs. (5) and (6), the ratio of the detected to generated photon pulses is then

$$
\begin{aligned}
R & =\frac{N_{\mathrm{M}}}{N_{\mathrm{I}}}=\frac{P(k=1)}{P(k \geq 1)}=\frac{\mu \cdot e^{-\mu}}{1-e^{-\mu}} \\
& \approx \frac{\mu \cdot e^{-\mu}}{1-\left[1-\mu+\frac{\mu^{2}}{2}-\ldots\right]} \approx e^{-\mu} .
\end{aligned}
$$

By replacing $\mu$ from Eq. (3), Eq. (7) can be written as

$R=\frac{N_{\mathrm{M}}}{N_{\mathrm{I}}}=e^{-N_{\mathrm{I}} \cdot \tau}$.

In the Brewer software, Eq. (8) is applied separately to the count rates for slit-mask positions 3,5 and 7 , by setting $N_{\mathrm{I}}^{0}=$
$N_{\mathrm{M}}$ as an initial guess and then by iterating (index $j$ ) over the rearranged expression:

$N_{\mathrm{I} i}^{j+1}=N_{\mathrm{Mi}} \cdot e^{N_{\mathrm{I} i}^{j} \cdot \tau^{j}}$.

For each iteration $\tau^{j}$ is determined by

$\tau^{j}=\frac{1}{N_{\mathrm{I} 7}^{j}} \cdot \ln \left(\frac{N_{\mathrm{I} 7}^{j}}{N_{\mathrm{M} 7}}\right)$, with $N_{\mathrm{I} 7}^{j}=N_{\mathrm{M} 3}^{j}+N_{\mathrm{M} 5}^{j}$.

After 10 iterations of Eqs. (9) and (10), $\tau$ converges to a value that defines DT.

Once DT is determined, the signals (count rates) measured by the Brewer are corrected for the dead time effect through

$N_{\mathrm{I}}^{j+1}=N_{\mathrm{M}} \cdot e^{N_{\mathrm{I}}^{j} \cdot \tau}$.

After nine iterations of Eq. (11) the result converges to the corrected signal $N_{\mathrm{I}}^{9}$.

Given the Poisson nature of photon statistics, there are two formulas that are commonly used to calculate DT (Schätzel, 1986; Yu and Fessler, 2000), which depend on the nature of the counting system. For Brewers, the relevant algorithm is based on the assumption that all photons, either recorded by the counting system or lost, trigger a new dead time period (paralyzable system) and the extended formula (Eq. 8) is used. If it is assumed that the dead time is triggered only by the photons that are recorded by the counting system (nonparalyzable system) then the following, non-extended, formula applies (Schätzel, 1986; Yu and Fessler, 2000):

$R=\frac{1}{1+\tau \cdot N_{\mathrm{I}}}$

Equation (12) is derived from Eq. (8) by assuming a very small value of $\tau$ and by replacing the exponential term with its Taylor expansion. Though, it describes more accurately the effect of dead time on non-paralyzable systems (Schätzel, 1986; Yu and Fessler, 2000). Subsequently, a new formula corresponding to Eq. (11) can be derived:

$N_{\mathrm{I}}^{j+1}=N_{\mathrm{M}} \cdot\left(1+\tau \cdot N_{\mathrm{I}}^{j}\right)$.

Although the extended formula is used in the Brewer operating algorithm, it is debatable whether the photon counting system of the Brewer is paralyzable or not. Kiedron (2007) has questioned the appropriateness of this formula for use in Brewers. Additionally, the simplifications of Eq. (7) and the assumption that $N_{\mathrm{I} 7}=N_{\mathrm{M} 3}+N_{\mathrm{M} 5}$ in Eq. (10) that are assumed in the Brewer algorithm could lead to systematic underestimation of DT and subsequently to underestimation of the corrected signal. These concerns are addressed in the following. 
(a)

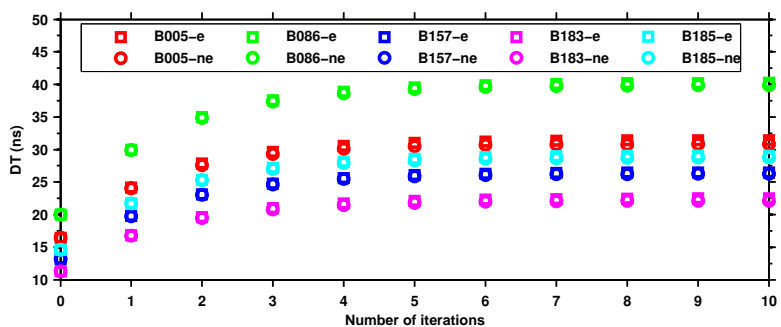

(b)

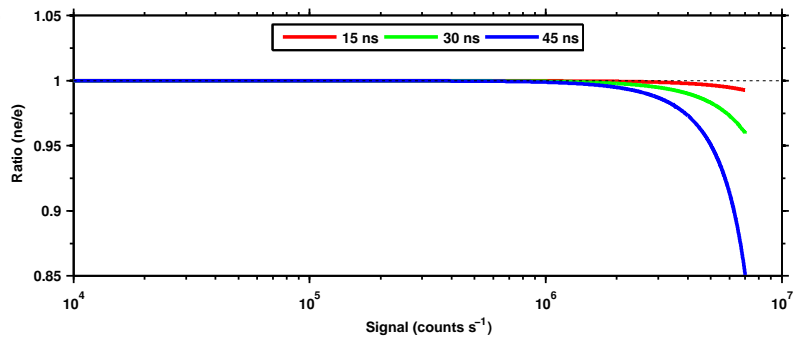

Figure 1. (a)Dead time derived with the extended (e) and the nonextended (ne) approach for five Brewers with DT ranging from 19 to $42 \mathrm{~ns}$ as a function of the number of iterations. (b) Ratio between signals corrected using the non-extended and the extended approach as a function of the logarithm of the measured, uncorrected for the dead time, signal (in counts $\mathrm{s}^{-1}$ ), for three different values of DT.

\subsection{Experimental evaluation of the determination of DT}

\subsubsection{Extended and non-extended formula}

The DT for five Brewers was calculated using the two different approaches, expressed by Eqs. (11) and (13), in order to assess the resulting differences. Typical count rates from the high-intensity dead time test of the Brewer operating software were used in the calculations. The results are presented in Fig. 1a. For both cases the calculated DT converges after 10 iterations, while the differences in the final DT are negligible. Specifically, the DT derived from the non-extended formula (Eq. 13) is smaller by less than $0.5 \mathrm{~ns}$ than the DT from the extended formula (Eq. 11).

In order to estimate the differences in the final products for a paralyzable and a non-paralyzable system, signals from 0 to $7 \times 10^{6}$ counts s $^{-1}$ were assumed and corrected for the dead time effect using both formulas for DT values ranging from 15 to $45 \mathrm{~ns}$ (Fig. 1b). It is noteworthy that the corrected signal was found to converge after 4-5 iterations, for both methodologies. This implies that it might not be necessary to use nine iterations in the Brewer software for the correction of the signal. For signals below $\sim 2 \times 10^{6}$ counts s $^{-1}$ the differences between the corrected signals with the two methods are less than $0.5 \%$. For higher signals the differences become more important; though, as long as the signal is below $\sim 3 \times 10^{6}$ counts s $^{-1}$, the differences are still less than $1.5 \%$. Thus, even if the Brewer counting system is non-paralyzable, the currently used algorithm does not induce important errors for the usual range of signals in direct-Sun measurements (between 0 and $2 \times 10^{6}$ counts $\mathrm{s}^{-1}$ ). For signals higher than $\sim 3 \times 10^{6}$ counts s$^{-1}$, which are common for global UV irradiance measurements, and for DT greater than $30 \mathrm{~ns}$, the corrected signal may be significantly overestimated.

\subsubsection{Artificial biases}

In order to determine the conditions under which the standard Brewer algorithm does not induce artificial biases in the results the following procedure was followed: theoretical values for the measured count rates $N_{\mathrm{M}}$ were estimated from Eq. (8) assuming different rates of photon pulses $N_{\mathrm{I}}$ and different reference DT values and the DT was recalculated from Eqs. (9) and (10). As long as the ratio of signals at positions 3 (or 5) and 7 of the slit mask, $N_{3} / N_{7}$ (or $N_{5} / N_{7}$ ), remains between 0.25 and 0.5 and the signal at position $7\left(N_{7}\right)$ remains below $10^{7}$ counts s $^{-1}$, the calculated and the reference DT coincide.

When the internal standard lamp is used to calculate DT, the ratio $N_{3} / N_{7}$ is usually $\sim 0.4$ and 10 iterations of Eqs. (9) and (10) are enough to provide an accurate result. However, as it will be discussed later, if a different radiation source (e.g., the Sun) is used to derive DT then the ratio $N_{3} / N_{7}$ might be much smaller. As shown in Fig. 2, when this ratio is less than $\sim 0.25$, more iterations are needed to achieve an accurate estimate of DT; otherwise DT is underestimated. For $N_{3} / N_{7}$ above 0.05 , at least 50 iterations are required to derive an estimate close to the reference DT, while for $N_{3} / N_{7}$ above 0.01 the required number of iterations increases to 300 (V. Savastiouk, personal communication, 11 January 2016). The results shown in Fig. 2 were found independent of the signal at position 7 for signal levels between $10^{2}$ and $10^{7}$ counts $\mathrm{s}^{-1}$.

\subsubsection{Dark signal}

In the Brewer algorithm, prior to the dead time correction, the dark signal is subtracted from the measured signal (Kerr, 2010). However, Kiedron (2007) suggested that before subtracting the dark signal both the measured and the dark signals should first be corrected for the dead time effect. In the same study it was suggested that even though the dark pulses have no Poisson distribution, the correction of both the dark and the measured signals through Eq. (12) should lead to more accurate signals than without applying dead time correction to the dark signal.

To assess the importance of this suggestion, an attempt was made to quantify the differences arising in the final signals. Different levels of measured signals, ranging from 0 to $7 \times 10^{6}$ counts s $^{-1}$, were assumed, as well as dark signals, ranging from 0 to $10^{5}$ counts $\mathrm{s}^{-1}$, which were added to the former. The derived signals were corrected for the dead time effect and the dark signal using both methods (operational in Brewers and suggested by Kiedron, 2007) and the resulting 


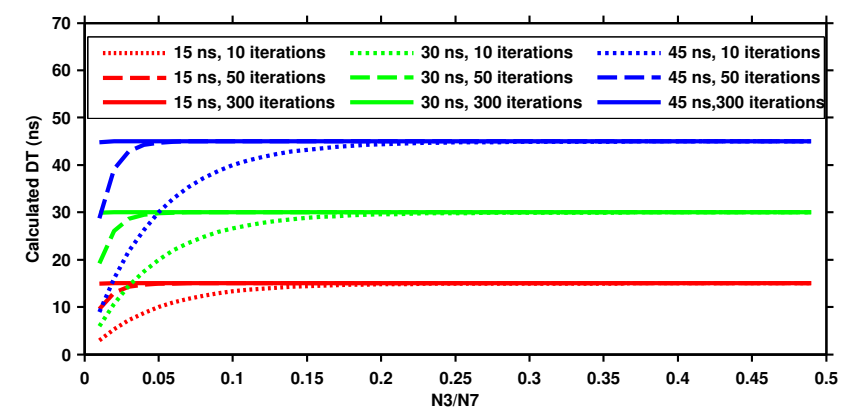

Figure 2. DT as derived by the standard Brewer software as a function of the ratio of signals at slit-mask positions 3 and $7\left(N_{3} / N_{7}\right)$ and for three different reference DT values (15, 30 and $45 \mathrm{~ns})$ using 10,50 and 280 iterations.

corrected signals were compared. The differences are smaller than $0.2 \%$ for dark signals below $10^{4}$ counts $\mathrm{s}^{-1}$. Considering that the dark signal in Brewer measurements during normal operation is generally well below this level, the correction of the dark signal for the effect of dead time would not have an important impact on the final results. For exceptional cases when the dark signal exceeds this limit, the difference increases fast but stays below $\sim 1 \%$ even for a dark signal of $10^{5}$ counts s $^{-1}$ and for DT of $45 \mathrm{~ns}$.

\subsubsection{Simplifications in the algorithm}

In order to assess the effect of the simplifications in Eq. (7) or due to other issues that have not been taken into account, the following experiment has been made. Spectral measurements of the radiation emitted by three different sources (the Sun, an external $1000 \mathrm{~W}$ DXW lamp and the internal $20 \mathrm{~W}$ standard lamp) were performed in steps of $5 \mathrm{~nm}$ for the operational spectral range of the Brewers that were used. Different levels of the signal were achieved using the internal ND filters, different distances (for the external lamp) or different solar zenith angles (SZAs) (for the Sun). Measurements of the $1000 \mathrm{~W}$ lamp (serial number 1005) were performed at the Izaña Atmospheric Research Center for different distances ranging from 40 to $115 \mathrm{~cm}$, measured between the lamp and the center of the quartz window of the Brewer. The lamp mount could move vertically on a metal rod of $1 \mathrm{~m}$ length. When an external lamp is positioned at such short distances, the geometry of the radiation entering the fore-optics of the Brewer is very different from the geometry of the Sun's rays. Additionally, for different distances the radiation does not necessarily originate from the same area of the lamp's filament (Kazadzis et al., 2005). However, for the specific experiment these factors are not important because measurements at different positions of the lamp are not compared to each other. What is important is that the spectrum of the emitted radiation does not change during measurements for each specific position of the lamp. This was ensured by monitoring continuously the intensity and the voltage of the lamp.
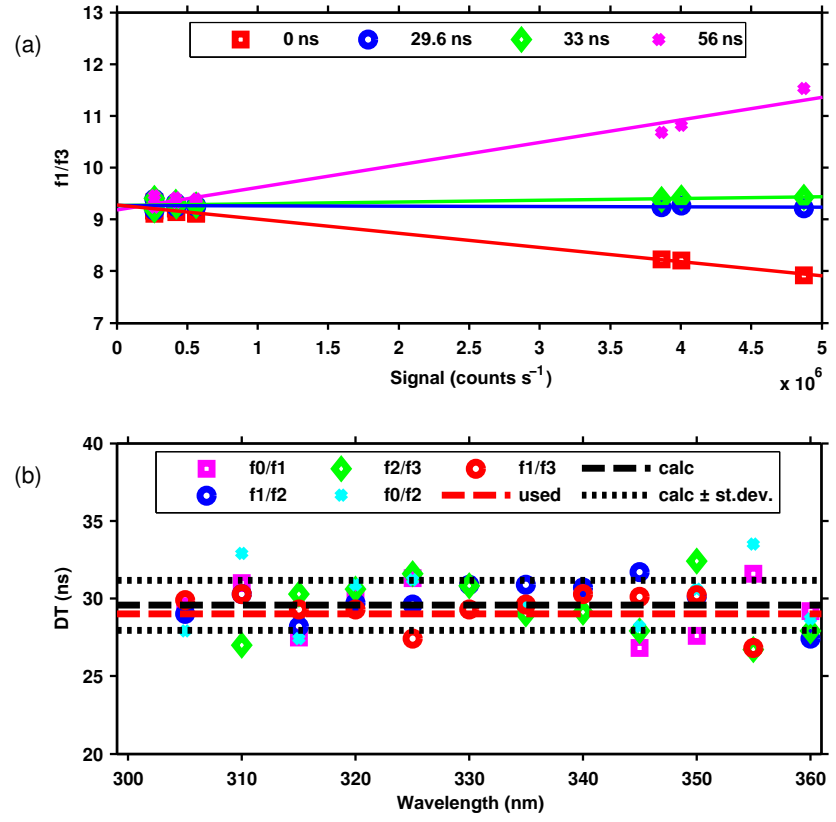

Figure 3. (a) Ratio of signals at $345 \mathrm{~nm}$ measured with ND filters 1 and 3 (optical densities 0.5 and 1.5) and corrected with four different values of DT as a function of the signal measured with ND filter 1. (b) The optimum calculated DT for different wavelengths and different relative attenuations (pairs of ND filters). The derived mean values and the used DT are also shown. All the results are for B185.

The relative attenuation between different ND filters was calculated (Sellitto et al., 2006; Redondas et al., 2011) for the standard lamp, for different distances of the external lamp and for different angles of the Sun. All measurements were corrected for the dead time using several values of the DT ranging from 0 to about twice the used DT in steps of $0.1 \mathrm{~ns}$. Then, spectral ratios of the signals (relative attenuation) for all pairs of ND filters were calculated. Assuming that the response of each instrument is nonlinear (intensity dependent) exclusively due to dead time effect, correction of the signal with the proper DT (and method) should eliminate the nonlinearity. For all wavelengths, the optimal correction should lead to ratios that are independent of the intensity of the incident radiation. This also suggests that correcting the measurements used to derive the relative attenuation of the ND filters with a wrong DT might lead to significant errors. For these measurements, it is important that the high voltage of the PMT is optimal and that the separation between signal and noise works properly, otherwise the results may be misleading. An example for one pair of ND filters and one wavelength is shown for B185 in Fig. 3. From Fig. 3a, the optimum DT for which the calculated attenuation is independent of the measured signal is found at $29.6 \mathrm{~ns}$ while for different values of DT the derived relative attenuation depends on the level of the signal. 
The above described procedure was repeated for all wavelengths and for all possible combinations of filters. Measurements for which the precision, according to Eq. (1), is lower than $2 \%$ were not used in the analysis, as well as measurements with signals (before applying the dead time correction) above $5 \times 10^{6}$ counts $^{-1}$. Additionally, some outliers resulting from spikes (Meinander et al., 2003) were rejected by visual inspection. The mean DT and the corresponding standard deviation were then calculated and are shown in Fig. $3 b$. For B185, the DT that yields the optimum correction is very close to the DT in use and the mean DT calculated regularly from the standard lamp measurements. The standard deviation is nearly $2 \mathrm{~ns}$.

The same test was performed using B086, operating in Thessaloniki. In this case moving the $1000 \mathrm{~W}$ lamp vertically was impossible; thus the lamp was fixed at a standard distance of about $40 \mathrm{~cm}$ from the center of the quartz window and different intensities were achieved by adjusting the current of the lamp. The test was performed for two periods with different calculated mean DT. In both cases the results were within $\sim 1$ ns from the mean DT calculated with the standard procedure, and the standard deviation was again of the order of $2 \mathrm{~ns}$. The test is more uncertain when applied on singlemonochromator Brewers, mainly due to the stray-light effect (Karppinen et al., 2014, and references therein).

If the counting systems of B086 or B185 were nonparalyzable the corrected signal would be significantly over-

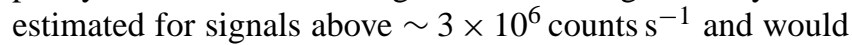
lead to overestimation of the ratios. Thus the estimated DT from the ND filters that provides the optimal correction would be lower than the DT calculated from the standard lamp. The fact that this is not happening is a strong indication that the photon counting systems of B086 and B185 are paralyzable, so the correction of the measurements using the extended formula is accurate. The results also reveal that the algorithm currently used is reliable and provides an accurate estimation of the DT.

\subsection{Determination of DT from solar measurements}

Using the standard lamp as a radiation source for the determination of the DT may occasionally lead to uncertain and noisy results, especially when the signal of the lamp (thus the accuracy of the measurements) is weak. In such cases, in addition to errors induced in the correction of the measured signals, it is difficult to detect possible problems (of mechanical or electronic origin) that may affect the determination of the DT. The operation of the lamp is not independent of the operation of the other electronic circuits of the instrument. Thus, it is not always easy to detect whether the observed changes in DT are real. The Sun is a more reliable and stable (under specific conditions) source compared to the standard lamp; thus using the solar measurements for the calculation of the DT would eliminate a great part of the uncertainties. Problems may arise when the Sun is partially or fully covered by clouds, resulting to rapidly changing or very low intensity, respectively, and increased uncertainties in the determination of DT. Thus, this method is unsuitable for locations with long periods of cloudiness. Other factors that may increase the uncertainty of the derived DT are changes in intensity of direct solar radiation due fast changes in the SZA early in the morning or late in the evening and in the concentration of various absorbing or scattering atmospheric constituents.

New routines for the determination of the DT from directSun measurements were developed and tested on Brewers 005, 086, 157, 183 and 185 for a period of about 10 months. The methodology is very similar to that used with the standard lamp (Sect. 2.1), but the number of iterations has increased from 10 to 50, to avoid underestimation of the calculated DT due to small values of the ratio $N_{3} / N_{7}$. Concerning the measurement procedure, the zenith prism is directed towards the Sun, appropriate ND filters are used to avoid overexposure of the PMT, and the DT is calculated only for one signal level, instead of 2 (high and low intensity) that are used with the standard lamp. The implementation of the specific routine aims mainly at reducing the uncertainty in the DT calculation, as complementary to the standard algorithm that uses the standard lamp. Measurements at two different signal levels are not applicable in this case, since the DT is calculated for a wide range of intensities due to the large temporal variability of solar radiation. Usually 10 cycles of the slit mask were used for each DT measurement. For a certain period the routine was run in B185 with 40 cycles in order to increase the accuracy in the determination of the DT.

At Thessaloniki, five consecutive measurements were performed each time and then the mean DT and the standard deviation were derived. The gratings of B086 were moved to a position where the ratio $N_{3} / N_{7}$ remains between about 0.3 and 0.5 . At Izaña, the mean DT and the standard deviation were derived from four consecutive measurements, with the gratings set at the ozone measurement position. In this analysis all measurements with standard deviation higher than $1.5 \mathrm{~ns}$ and with signal at position 7 below $10^{5}$ counts $\mathrm{s}^{-1}$ were rejected. To avoid very low signal levels at positions 3 and 5, only measurements for $N_{3} / N_{7}$ ratios between 0.15 and 0.85 were used. In Fig. 4 , the DT derived for three of the five Brewers investigated is presented as a function of day of the year (DOY).

For B086, the DT derived from the standard lamp is much noisier than from the Sun during the first months of the year. This is due to the very low intensity of the standard lamp used in that period. In April (DOY 94) the standard lamp was replaced with one of higher intensity, which resulted in substantial reduction of the noise in the estimated DT. Further improvement in the DT results can be observed after DOY 142, when the number of cycles was increased from 10 to 20 . During the analyzed period, the DT derived from direct-Sun measurements is very stable and less noisy than the DT from the standard lamp (from both high- and lowintensity measurements). Prior to August 2014 (DOY 220) 

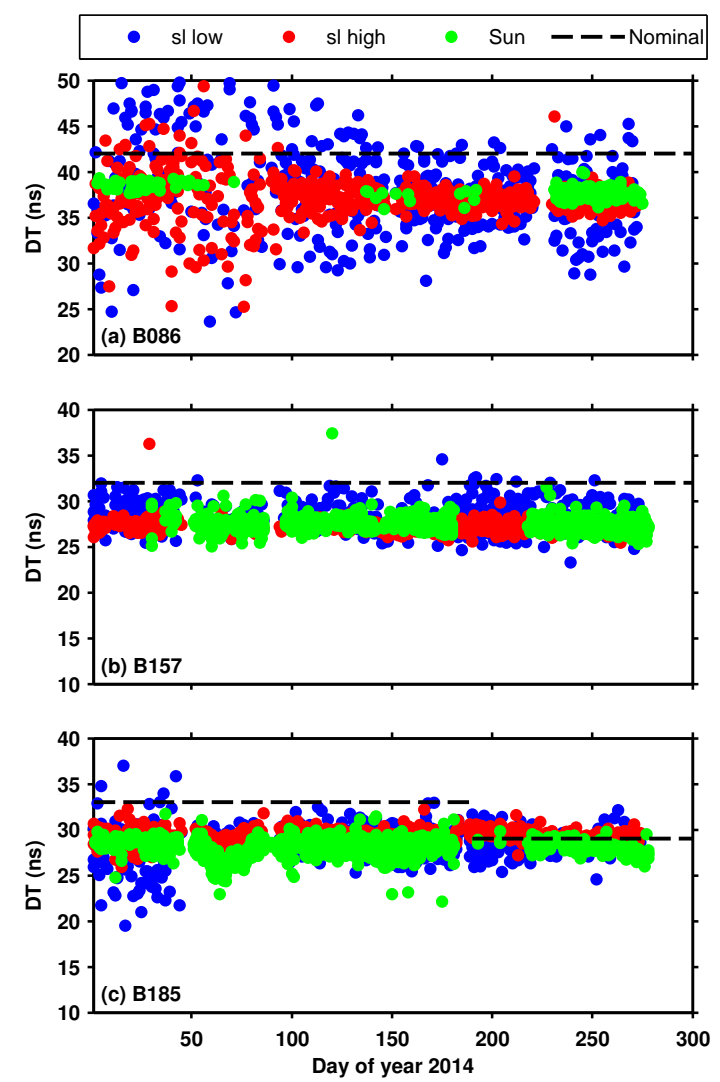

Figure 4. DT calculated from measurements of the standard lamp (high and low intensity) and the Sun as a function of day of year 2014 for three Brewers: (a) B086, (b) B157 and (c) B185. Dashed lines represent the DT used by the instruments in each period.

the direct-Sun-based determination of the DT was performed only once per day near the local noon (SZAs ranging from $\sim 63^{\circ}$ in December to $\sim 17^{\circ}$ in June) in order to achieve stable and high-intensity signal. Although the noise was very low during that period, there are too few measurements available. Since the beginning of August, several measurements were performed each day at different SZAs between $\sim 75^{\circ}$ and the local noon; thus the amount of available data has increased but also the noise. The response of B086 is low; therefore reduction in intensity is reflected immediately on the estimated DT. The DT derived during the period of study is about 38-39 ns, 3-4 ns lower than the used DT, and is independent of the radiation source.

For B157, the agreement between the DT from the standard lamp and the Sun is very good. Some outliers in DT derived from the direct-Sun measurements are due to data of low intensity recorded at large SZAs. As for B086, the DT derived for B157 from both the standard lamp and the Sun is 4-5ns lower than the DT of $32 \mathrm{~ns}$ used in regular operation. Considering that B157 is one of the standard Brewer triad instruments of AEMET, the DT used for the signal correction should be reduced by $4-5 \mathrm{~ns}$, at least for the specific period. The most possible reason for the difference between the calculated and the used DT is the gradual change of the characteristics of the photon counting system.

For B185, the second triad Brewer, the results are similar with B157. For the first part of 2014 (before DOY 190), the mean measured DT is lower than the used DT during this period. In this day the operationally used DT was changed from 33 to $29 \mathrm{~ns}$, after ensuring that no realignment of the optics and no resetting of the PMT were needed, following the suggestions of Grajnar et al. (2008). The mean DT from the Sun and the standard lamp are in good agreement during the entire period of measurements. After DOY 190 the spread in the DT from the direct-Sun measurements is smaller compared to the previous period (and compared to the high-intensity DT from the standard lamp) as a result of the increase in the number of cycles from 10 to 40 . The conclusions from the analysis of the DT for B086, B157 and B185 are valid also for B005 and B183; thus their results are not presented.

Rodriguez-Franco et al. (2014) suggested that the calculated DT is not necessarily the one which provides the optimal signal correction and further investigation is needed. The present study showed that the procedure used for the determination of the DT provides accurate results as long as the measurements are performed under appropriate conditions (as already discussed in Sects. 2.1-2.3 and further discussed in Sect. 2.5). However, even if the correct DT is known and used, there are other factors that might lead to nonlinear responses of the photon detection system which might be falsely perceived as improper DT correction.

\subsection{Factors affecting the determination of DT}

In order to determine the optimum instrumental settings for the calculation of the DT, continuous direct-Sun measurements were performed in Izaña with B185 during two consecutive cloud-free days with nearly zero aerosol optical depth. Every about $40 \mathrm{~min}$, five consecutive DT measurements were performed using each time different grating settings, corresponding to different wavelengths at the two exit slits. The five wavelengths corresponding to position 3 of the slit mask are 306.3, 317, 331.5, 345 and $354.5 \mathrm{~nm}$, while for position 5 the five wavelengths are about $7 \mathrm{~nm}$ longer. This way, measurements for different intensities, wavelengths and $N_{3} / N_{7}$ ratios were performed for very similar SZAs and atmospheric conditions. During the first day, 40 cycles were used for the first set of wavelengths (306.3 nm at position 3) and 10 cycles for the other four sets. During the second day, the number of cycles was changed to 10 and 5 , respectively.

Due to the different combinations of wavelengths the recorded $N_{3} / N_{7}$ ratio ranges from 0.05 to 0.5 . The DT derived from measurements with $N_{3} / N_{7}$ ratios between 0.15 and 0.5 is very close to the used DT $(29 \mathrm{~ns})$. For the same value the optimum dead time correction was achieved, as discussed in Sect. 2.3. For ratios lower than 0.15 the spread of the derived DT is very large and its mean values are smaller 
than the used DT, even after 10000 iterations of Eqs. (9) and (10), possibly due to the increased noise in the lowerintensity measurement (at position 3 or 5). The intensity of radiation does not affect the calculated DT but is important for the uncertainty of the measurements. The calculated standard deviation decreases with increasing signal. For signal at position 7 between 500000 and 1000000 counts s $^{-1}$ the standard deviation of DT is smaller than $5 \%(\sim 2 \mathrm{~ns})$ when 10 or more cycles are used in the measurements. For signals higher than $10^{6}$ counts s$^{-1}$ the standard deviation is below $3 \%(\sim 1 \mathrm{~ns})$ and decreases even more for higher signals. A larger number of cycles leads to smaller standard deviation and therefore reduced uncertainty in the determination of the DT. When the number of cycles increases from 5 to 10 the standard deviation decreases by a factor of 2 . The same fractional decrease in the standard deviation is found also when the number of cycles increases from 10 to 40 . It should be noted that no wavelength dependence was detected in the determination of the DT. Finally, calculation of the DT using the standard lamp for different temperatures within a specific day revealed no changes for temperatures ranging from 17 to $35^{\circ} \mathrm{C}$.

\section{Effects of dead time on the uncertainties of the final products}

In the following, an attempt is made to quantify the main uncertainties in the calculation of UV irradiance, TOC and AOD due to errors in the estimation of the DT. Effects in the calculation of the total columns of $\mathrm{SO}_{2}$ and $\mathrm{NO}_{2}$ are not discussed, because uncertainties from other sources are much higher due to the usually small column amounts (the order of a few DU) of these species (Fioletov et al., 1998; Wenig et al., 2008). Errors in DT are also expected to affect the results of different diagnostic tests in the Brewer, such as the measured intensity of the internal lamps and the determination of the transmittance of the ND filters, which in turn may affect the accuracy of the final products. Although it is difficult to quantify these uncertainties, they are believed to be of less importance compared to those discussed below.

\subsection{UV irradiance}

The spectral irradiance measured by the Brewer generally ranges between $10^{-6}$ and $1 \mathrm{~W} \mathrm{~m}^{-2}$ and is calculated by multiplying the corrected for the effect of dead time signal $N_{\mathrm{I}}$ with a proper calibration function. Thus, uncertainties in $N_{\mathrm{I}}$ due to inaccurate DT correction of the raw signal $N_{\mathrm{M}}$ are directly transferred to the final product. The effect of a specific error in DT on UV irradiance depends on the measured signal $N_{\mathrm{M}}$ and the actual value of the DT, and it can be estimated by Eq. (11). Figure 5 shows the effect on irradiance caused by deviations in the used DT in the range \pm 2 to $\pm 10 \mathrm{~ns}$ from three characteristic reference values as a function of $N_{\mathrm{M}}$.

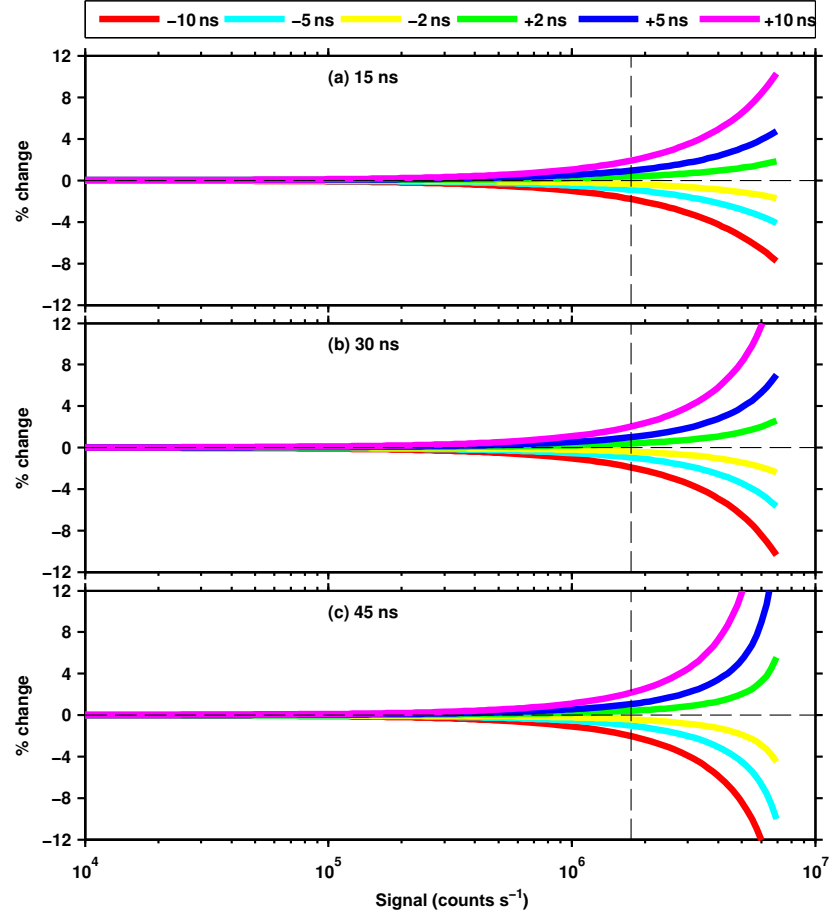

Figure 5. Changes in UV irradiance as a function of the measured signal due to errors in the determination of DT, for different values of the reference DT: (a) $15 \mathrm{~ns}$, (b) $30 \mathrm{~ns}$ and (c) $45 \mathrm{~ns}$. The vertical dashed line marks the cut-off limit of $\sim 1.75 \times 10^{6}$ counts s $^{-1}$ used for direct-Sun measurements.

The effect of an error in DT was investigated for signals in the range $0-7 \times 10^{6}$ counts $^{-1}$. For direct-Sun measurements that are used for the retrieval of TOC and AOD the signal is usually kept below $\sim 1.75 \times 10^{6}$ counts $^{-1}$ (dashed line in Fig. 5) using ND filters. As long as the signal remains below that level, even a large change of $10 \mathrm{~ns}$ in DT leads to a corresponding change in the calculated irradiance of up to about $2 \%$. For higher intensities the effect increases fast, so that for signals near $5 \times 10^{6}$ counts s $^{-1}$ a change in DT of only $2 \mathrm{~ns}$ - a level that is commonly encountered in Brewers - causes $\sim 2 \%$ change in irradiance. Larger deviations, however, result in larger errors in irradiance that cannot be neglected. For example, a $10 \mathrm{~ns}$ change in DT leads to differences in irradiance from 5 to $12 \%$, depending on the actual value of DT.

Given that for a properly maintained instrument the DT used for the correction of the measurements does not differ by more than $\pm 2 \mathrm{~ns}$ from the calculated DT, we can estimate the fractional $1 \sigma$ uncertainty in the measured UV irradiance based on the work of Bernhard and Seckmeyer (1999) and the results presented in Fig. 5:

$u=\frac{E(-2 \mathrm{~ns})+E(+2 \mathrm{~ns})}{2 \cdot \sqrt{3}}$, 
where $E(-2 \mathrm{~ns})$ and $E(+2 \mathrm{~ns})$ are the errors in UV irradiance due to corresponding errors of -2 and $+2 \mathrm{~ns}$ in the used DT, respectively. For DT values between 15 and $45 \mathrm{~ns}$, the $1 \sigma$ uncertainties are $0.12-0.13,0.25-0.28$ and $0.69-1.13 \%$ for signals of 1, 2 and 5 million counts $\mathrm{s}^{-1}$, respectively. For a sampling time of $\sim 2.3 \mathrm{~s}$ (20 cycles), which is commonly used in direct-Sun measurements to derive TOC and AOD, the combined uncertainty due to photon noise and DT errors is less than $\sim 0.2 \%$, as long as the measured signal is between $10^{5}$ and $\sim 1.75 \times 10^{6}$ counts s ${ }^{-1}$. For a shorter sampling time, $\sim 0.23 \mathrm{~s}$ ( 2 cycles), commonly used in spectral UV scans, the same uncertainty of less than $\sim 0.2 \%$ occurs for signals between $\sim 10^{6}$ and $1.75 \times 10^{6}$ counts $\mathrm{s}^{-1}$. Finally, for sampling times between $\sim 0.1$ and $4.5 \mathrm{~s}$ (corresponding to $1-40$ cycles) the signal with the minimum uncertainty lies between 0.5 and 1.5 million counts s ${ }^{-1}$. Below and above the specific range, the uncertainties are dominated by photon noise and dead time, respectively.

In order to quantify the errors in global spectral irradiance measurements due to uncertainties in the determination of the DT, data from Brewers operating in Thessaloniki and Izaña were processed using different values of the DT. For B086, the recorded signal for global UV irradiance measurements barely exceeds $2 \times 10^{6}$ counts s$^{-1}$, even at very small SZAs. Thus, a change of $10 \mathrm{~ns}$ in DT, relative to the value in use (42 ns), leads to a change in the noon spectral irradiance of less than $2 \%$ at UVA wavelengths (strong radiation) during a cloud-free and low-aerosol day near the summer solstice $\left(\sim 17^{\circ} \mathrm{SZA}\right.$ in Thessaloniki). At SZAs larger than $60^{\circ}$ the maximum measured signal is usually less than $10^{6}$ counts s ${ }^{-1}$ and the uncertainties due to DT errors are negligible. However, at short wavelengths (e.g., $\lambda<305 \mathrm{~nm}$ ) the signal is usually of the order of $10^{4}$ counts $\mathrm{s}^{-1}$ or lower, so the $1 \sigma$ uncertainty of the measurements solely due to the photon noise is $2 \%$ or higher. A much smaller change of $2 \mathrm{~ns}$ in the DT for B185 (DT in use $29 \mathrm{~ns}$ ), for which the recorded signal may exceed $6 \times 10^{6}$ counts $\mathrm{s}^{-1}$, is enough to cause a $2 \%$ change in noon irradiance $\left(\sim 6^{\circ} \mathrm{SZA}\right.$ in Izaña). Due to the different atmospheric conditions in Izaña (compared to Thessaloniki) and the higher responsivity of B185 (compared to B086), under cloud-free skies the signal of B185 at around $305 \mathrm{~nm}$ is usually higher than $10^{4}$ counts $\mathrm{s}^{-1}$ for SZAs smaller than $70^{\circ}$, and the $1 \sigma$ uncertainties due to photon noise are less than $\sim 2 \%$. For wavelengths in the UVB region, the effect of the dead time is negligible since the radiation is much weaker for both instruments.

\subsection{Total ozone column}

The retrieval of TOC with a Brewer spectrophotometer is based on the analysis of near-simultaneous direct-Sun spectral irradiance measurements at four wavelengths (Kerr et al., 1981). Five sets of measurements are performed within about $2 \mathrm{~min}$ and the mean TOC and the corresponding standard deviation are calculated. Before each set of measurements, the intensity of the irradiance is tested and an appropriate ND filter is used to keep the maximum recorded signal between $\sim 0.5 \times 10^{6}$ and $1.75 \times 10^{6}$ counts s$^{-1}$. For the retrieval of TOC the so-called extraterrestrial constant (ETC) is required (Kerr et al., 1981). The ETC can be either calculated using the Langley extrapolation method (Thomason et al., 1983) or transferred from a standard instrument through side-by-side comparison of TOC measurements (Fioletov et al., 2005).

Because the correction for the DT applies to measurements of irradiance and its effect depends on the level of irradiance, the effect on TOC depends basically on the differences in the signal at positions 3-6 of the slit mask (wavelengths 310.1, $313.5,316.8$ and $320.1 \mathrm{~nm}$ ). Such differences are caused by atmospheric influences on the solar spectrum (e.g., from ozone absorption, Rayleigh scattering and SZA) and by the shape of the spectral response of the instrument. The latter may significantly differ between instruments, particularly for Brewers of different type. For example, the presence of the $\mathrm{UG}_{11-\mathrm{NiSO}_{4}}$ filters combination in single-monochromator Brewers changes significantly the shape of the spectral response, compared to double-monochromator Brewers, leading to different correlation between the levels of irradiance measured at the four slits.

Although the shape of the spectral response differs between instruments which are equipped with different PMTs (e.g., for B086 and B185) these differences are not as important as between single- and double-monochromator Brewers. In the following, the effect of the DT correction on the determination of the ETC and the retrieval of TOC are discussed for the single-monochromator B005 and the doublemonochromator B185. The same analysis for the MKIII Brewers 157 and 183, not shown here, yielded similar results to those for B185.

\subsubsection{ETC from Langley plots}

To derive the ETC from Langley plots, continuous measurements of direct-Sun irradiance at wavelengths used for the calculation of TOC are performed during half days (morning to noon or noon to evening) with stable atmospheric conditions (clear skies, stable TOC, low and stable AOD). Then the ratio of the logarithms of signals used for the calculation of TOC is derived and plotted against the air mass (secant of the SZA for SZAs greater than about $75^{\circ}$ ). The ETC is the intercept of the resulting linear fit. Errors in the determination of DT may induce errors in the calculation of the ETC. Although ND filters are used to protect the PMT from exposure to very high intensities which are mostly affected by dead time, errors in DT are still important when the signal is near the high-intensity threshold. Langley plots for about 10 days were derived from measurements with the MKIII Brewers 157, 183 and 185 in Izaña and the MKII Brewer 005 in Thessaloniki. Although the atmospheric conditions in Thessaloniki are not usually favorable for application of the Langley method, a few days with relatively stable atmo- 

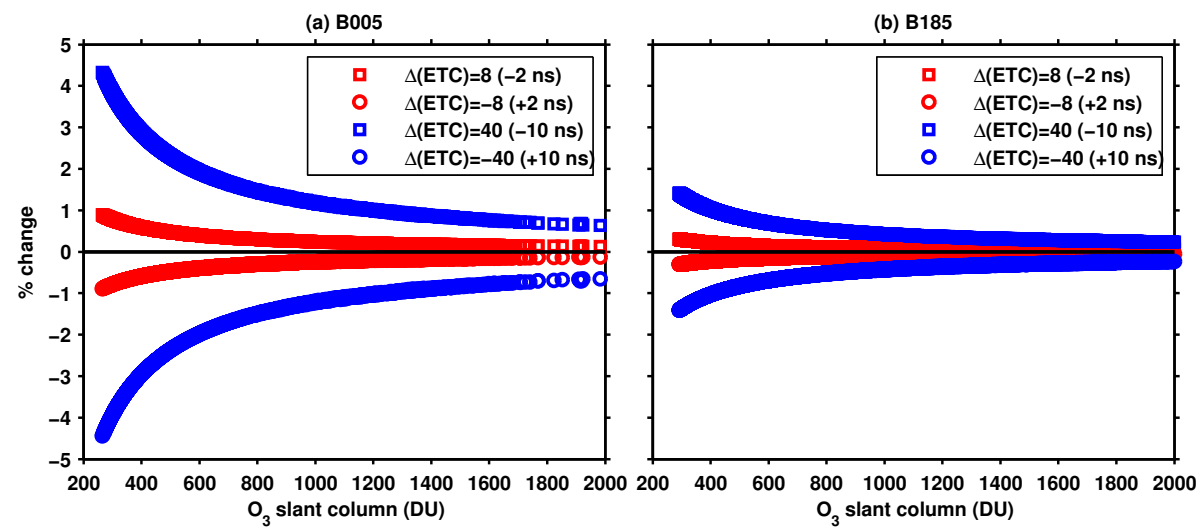

Figure 6. Changes (\%) in the calculated TOC due to changes in the ETC resulting from \pm 2 and \pm 10 ns change in DT, as a function of the slant column of ozone for B005 (a) and B185 (b). For B005 the used ETC has been changed by \pm 8 units for a \pm 2 ns change of the DT and by \pm 40 units for a $\pm 10 \mathrm{~ns}$ change of the DT. For B185, the corresponding changes of the ETC are \pm 3 and \pm 15 units.

spheric conditions were found in a 1-year record of measurements which were used indicatively for the purposes of this study. For the MKIII Brewers, the change in the derived ETC for a 2 ns change in DT is typically less than 3 units, rising to $\sim 15$ for a $10 \mathrm{~ns}$ change. The corresponding changes for the MKII Brewer are 8 and 40 units, respectively. Such errors in the determination of the ETC influence directly the calculated TOC. The differences between the two types of Brewers are mainly caused by differences in the shape of their spectral response.

\subsubsection{Effect of DT on direct-Sun measurements used in TOC retrieval}

In Fig. 6, changes in TOC due to changes in the ETC resulting from typical errors in DT are presented. The error in TOC increases smoothly with decreasing ozone slant column. For B185, the change in TOC due to a 2 ns change in DT is generally less than $0.5 \%$, rising to about $1.5 \%$ for a $10 \mathrm{~ns}$ change in DT, for slant ozone columns below $500 \mathrm{DU}$, while for B005 the corresponding changes are 1 and $4.5 \%$, respectively.

The effect of DT on TOC derived from direct-Sun measurements during 20 days in June 2013 in Thessaloniki (B005) and Izaña (B185) has been investigated, by applying different offsets to the DT that is used to correct the measured irradiances (Fig. 7). For this analysis, the ETC has been kept constant, irrespective of the used DT.

For all cases, the maximum changes in TOC occur just before (after) a ND filter of higher (lower) optical density is set. At this point the change in intensity is large and the dead time effect on the measured signal increases. This indicates that the effect on the calculated TOC becomes stronger for higher intensities. Additionally, the change in TOC increases as the ozone slant column decreases, due to stronger intensity of the incoming radiation and to changes in the distribution of radiation on different slits. In accordance with the results shown in Fig. 6, for small changes in DT $(\sim 2 \mathrm{~ns})$ the effect on TOC derived from B185 is small, generally, below $0.5 \%$, and for B005 up to $\sim 1.5 \%$. For larger changes in the DT $( \pm 10 \mathrm{~ns})$ the effect on TOC is no more negligible for B185 and much stronger for B005, occasionally reaching $5 \%$. The stronger effect of dead time on TOC derived from singlemonochromator Brewers was also confirmed by Redondas et al. (2011) and Rodriguez-Franco et al. (2014).

In old versions of the Brewer operating software, the selection of the ND filter to be used in a direct-Sun measurement is done through an automatic intensity check of the level of the signal at position $6(320.1 \mathrm{~nm})$. For double-monochromator Brewers, the signal at the other wavelengths (positions 3 5) is significantly weaker. Due to the shape of their spectral response, in single-monochromator Brewers and for small ozone slant columns the signal at positions 4 and 5 is higher compared to position 6 and occasionally higher than the threshold used to set a higher density filter. In such cases, the high-intensity signals are more susceptible to errors in DT, leading to errors in the derived TOC. As the ozone slant column increases the intensity at positions 4 and 5 decreases faster and gradually becomes smaller than at position 6 . Although the specific problem has been solved in more recent versions of the Brewer operating software, it remains important for past data sets or for instruments still operating with an old version of the software.

\subsubsection{Combined effect of DT on ETC and TOC}

In this section the combined effect of errors in DT on both the ETC derived by the Langley method and the direct-Sun measurements used in the retrieval of TOC is investigated. Specifically, the dead time effects on the ETCs that were estimated for B005 and B185 in Sect. 3.2.1 were applied to the ETC that is used in reprocessing the direct-Sun measurements. 


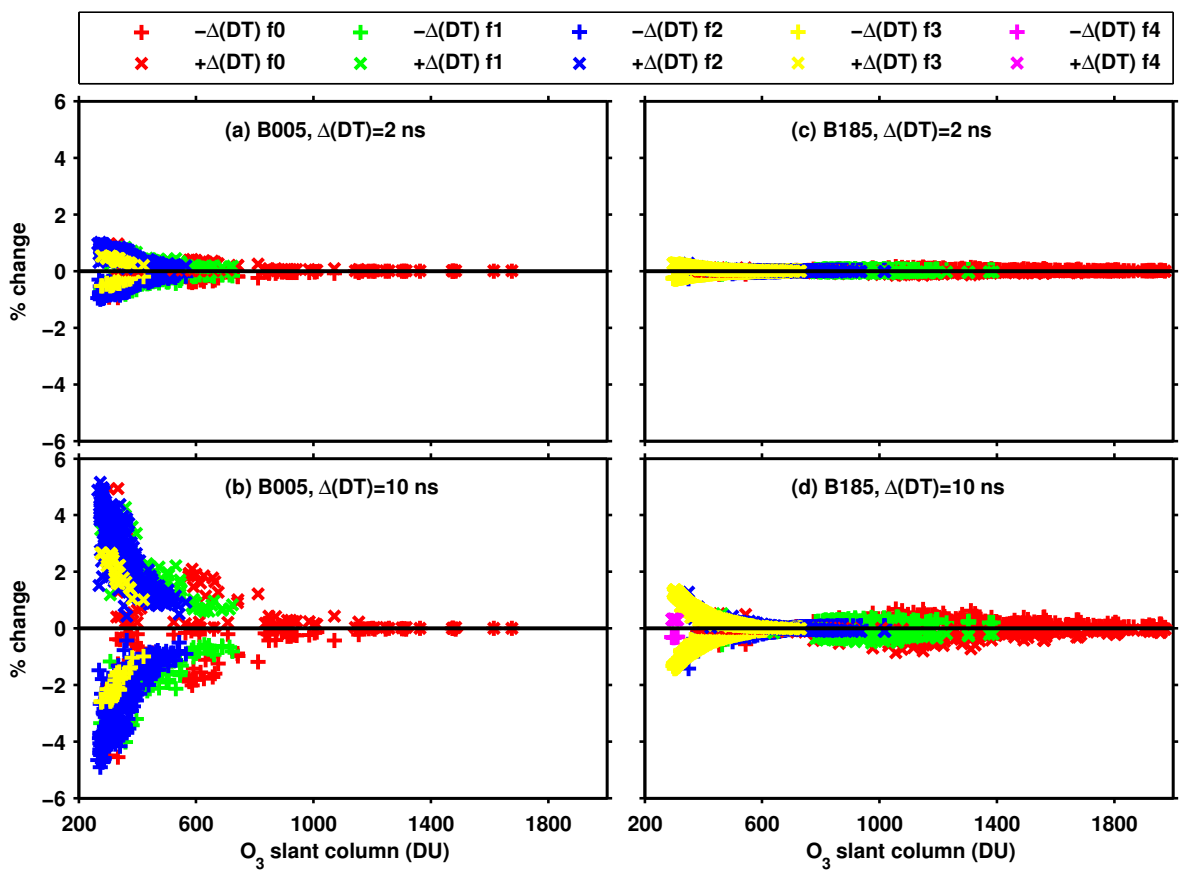

Figure 7. Changes $(\%)$ in TOC derived from direct-Sun measurements due to offsetting the DT by $\pm 2 \mathrm{~ns}(\mathbf{a}, \mathbf{c})$ and $\pm 10 \mathrm{~ns}(\mathbf{b}, \mathbf{d})$, as a function of ozone slant column, for B005 (a, b) and B185 (c, d). Different colors refer to data measured without (red) and with neutral density filters of optical density 0.5 (green), 1 (blue), 1.5 (yellow) and 2 (magenta). The reference DT is $34 \mathrm{~ns}$ for B005 and $29 \mathrm{~ns}$ for B185.

From Figs. 6, 7 and 8 it appears that the effect of falsely calculated ETC due to errors in DT lead to changes in TOC of opposite sign compared to those caused by the correction of the signal with wrong DT. The first is dominant for large ozone slant columns, while the second for small ozone slant columns. Specifically, for large ozone slant columns the results are similar with those of Fig. 6, while for small ozone slant columns the large changes in TOC shown in Fig. 7 are suppressed since the two effects are balanced. Even in this case, a $10 \mathrm{~ns}$ change in DT leads to $3 \%$ change in TOC for B005.

\subsubsection{Transfer of the ETC calibration from a reference instrument}

The ETC is usually transferred from a reference to the Brewer being calibrated, using a series of simultaneous TOC measurements. Possible errors in DT in either reference instrument or the instrument being calibrated may affect the calculation of the ETC. There are two different methods for transferring the ETC from the reference to the calibrated instrument (Redondas and Rodriguez-Franco, 2012): (1) the "one-point calibration", where only the ETC for the calibrated instrument is calculated, and (2) the "two-point calibration", where the differential ozone absorption coefficient is calculated at the same time with the ETC (Kerr et al., 1981). The effect of possible errors in DT depends on the method.
As shown in Fig. 7, errors in DT affect the TOC measurements significantly when the intensity of the signal is high and/or the ozone slant column is small. The difference in TOC due to the use of an incorrect DT cannot be eliminated simply by replacing the ETC that has been derived from the incorrect DT. As it appears from Figs. 7 and 8, although a change in the ETC may partially or fully counteract the TOC errors for small ozone slant columns and high intensities, it leads to larger deviations from the reference TOC for large ozone slant columns and/or low intensities. If the two-point calibration is used, the differences observed in Fig. 7 can be balanced by a combined change of the ETC and the differential absorption coefficient. This way, the change of the ETC would suppress the effect of the DT error for low ozone slant columns, while the change of the differential absorption coefficient would counteract the differences in TOC for large slant columns. It is obvious that the use of an incorrect DT leads to different ETCs between the one-point and the twopoint calibrations. The DT effect when transferring the ETC from a reference instrument cannot be easily quantified for none of the two methods. However, it is not expected to be more important than the impact of the same DT error on the ETC calculation with the Langley method.

\subsection{Aerosol optical depth}

Estimates of the AOD can be also derived from Brewer spectrophotometers using direct-Sun spectral measurements 


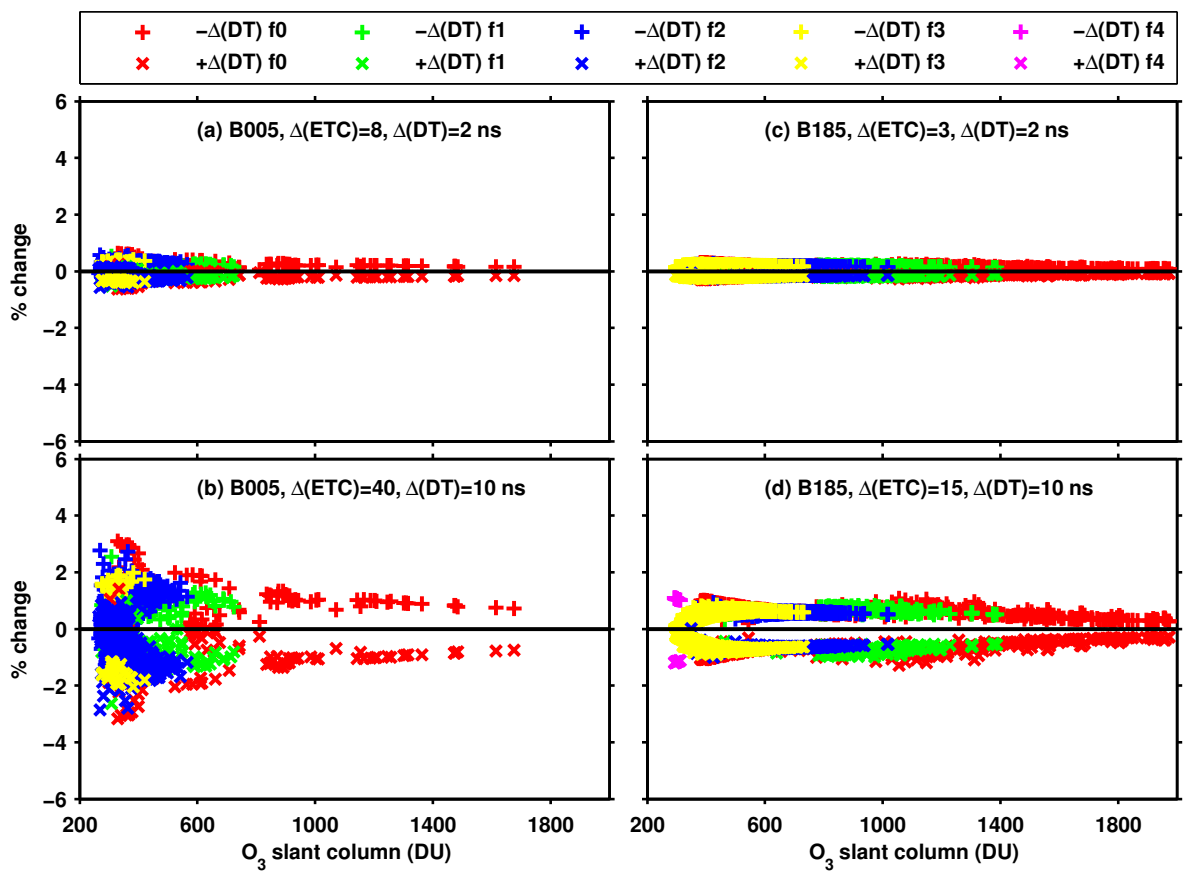

Figure 8. Changes (\%) in TOC calculated from direct-Sun measurements due to $\pm 2 \mathrm{~ns}(\mathbf{a}, \mathbf{c})$ and $\pm 10 \mathrm{~ns}(\mathbf{b}, \mathbf{d})$ changes in the DT, as a function of ozone slant column, for B005 (a, b) and B185 (c, d). For each change of the DT, the ETC used for the calculations is subjected to the changes described in Sect. 3.2.1. Different colors refer to data measured without (red) and with neutral density filters of optical density 0.5 (green), 1 (blue), 1.5 (yellow) and 2 (magenta). The reference DT is $34 \mathrm{~ns}$ for B005 and $29 \mathrm{~ns}$ for B185.

(Meleti and Cappellani, 2000; Kazadzis et al., 2007). As the error in AOD is equal to the natural logarithm of the ratio between the erroneous and the correct signal, divided by the air mass, changes in the measured irradiance of 1 and $5 \%$ lead to changes of opposite sign in the absolute levels of the derived AOD of about 0.01 and 0.05 , respectively, for air mass close to unity. As can be seen from Fig. 4, for very high intensities errors of this level may arise from changes in DT of 2 and $10 \mathrm{~ns}$, respectively. Considering that the overall absolute uncertainties in the calculation of AOD range between 0.05 and 0.07 (Kazadzis et al., 2007), only large DT errors, of the order of $10 \mathrm{~ns}$, have important effects, even if the AOD has been derived for small air mass using high-intensity measurements.

\section{Evaluation of the dead time for past data sets: Methods and difficulties}

As already mentioned, in a Brewer's history there might be periods when the calculated DT may differ from the one in use by more than $2 \mathrm{~ns}$. Interventions on the instrument, such as repairing the electronics, resetting the high voltage or realigning the optics, may result in suppression of the differences between the calculated and used DT (Grajnar et al., 2008; Kimlin et al., 2005). However, during regular operation it is not always easy to assess whether the derived DT is the actual and whether its application would improve the quality of the measurements. In addition, unusual day-to-day variations of the calculated DT or indications of temperature or intensity dependence complicate further this assessment. For such cases, only analysis of TOC measurements before and after an ND filter is set, or comparison with TOC derived from co-located instruments or from satellites, can reveal whether the measurements are properly corrected for nonlinearity effects. Spectral UV irradiance is more sensitive to changes in atmospheric constituents and SZA; thus it is more difficult to get the same information by comparing data sets of spectral UV irradiance.

For example, in June 2007 the preamplifier board of the PMT of B005 was replaced. Before the replacement the mean measured DT was $\sim 23 \mathrm{~ns}$ while the used DT was $34 \mathrm{~ns}$. After the repair the measured DT agreed very well with the DT in use. In order to assess whether the mean DT measured during the two different periods provides the optimal signal correction, the TOC record was recalculated from intensities corrected with the mean DT and compared with satellite data. The comparison was made for two periods: 1 month before and 1 month after the change of the preamplifier board. Data from the NASA EOS Aura satellite, which carries the Ozone Monitoring Instrument (OMI), were used. The specific satellite passes over Thessaloniki, where B005 is located, daily close to local noon. For the comparison only clear-sky measurements of TOC for air mass below 1.15 were used. The ratio of the TOC derived from the Brewer using two differ- 

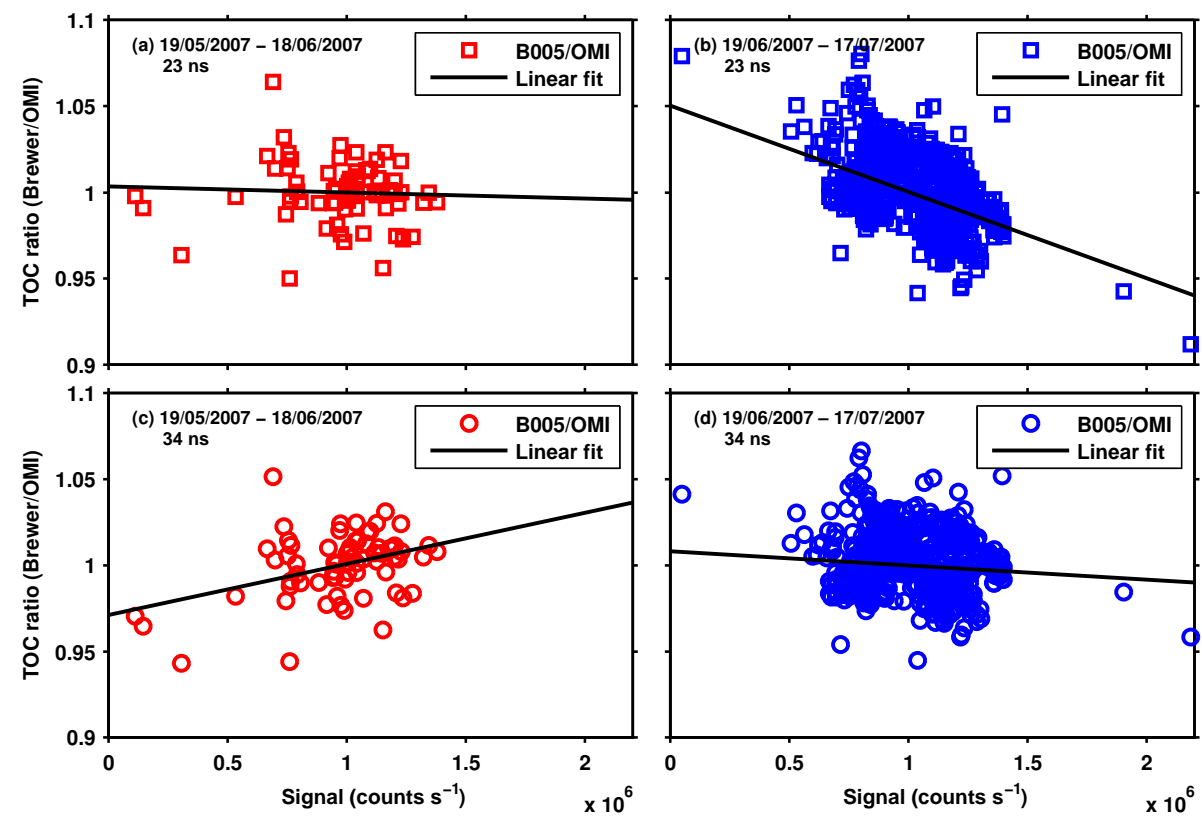

Figure 9. Ratio of TOC derived from B005 for different DT values and OMI, as a function of the Brewer measured signal at slit-mask position $5(320.1 \mathrm{~nm})$.

ent DT corrections (23 and $34 \mathrm{~ns}$, respectively) and the OMITO3 (Bhartia et al., 2002) was plotted as a function of the measured intensity at $320.1 \mathrm{~nm}$. If the Brewer measurements were properly corrected for nonlinearity the ratio would be independent of intensity. The ratios for the two periods, normalized with the mean over each period to remove absolute biases, are shown in Fig. 9.

For the first period, the ratio derived for the DT in use shows a clear dependence on intensity (Fig. 9c) which is practically removed when the measured DT was used (Fig. 9a). For the second period, the DT in use (which now coincides with the measured DT) results in very small dependence on intensity (Fig. 9d), whereas when the mean DT of the first period is used the dependence is strong (Fig. 9b).

In a similar study the DT for B070 was found $\sim 10 \mathrm{~ns}$ below the DT in use, but when it was applied to the data the agreement with the TOC of the reference B183 became worse (Rodriguez-Franco et al., 2014). It must be clarified in this point that if the TOC ratio of a Brewer and a reference instrument (ground based or satellite borne) is independent of intensity, this does not necessarily mean that the used DT is the actual DT of its photon counting system. The dead time correction may also compensate for instrumental malfunctions or settings that lead to real or artificial nonlinear behavior of the instrument, such as, for example, the combination of errors in the ETC and the differential absorption coefficient. Thus comparisons with TOC from other instruments provide an indication only of remaining nonlinearity issues after the correction for the dead time effect. Since nonlinearity in the measurements of TOC may not be exclusively due to dead time, the DT that provides the optimal correction is not necessarily the actual DT of the system. Therefore, it is safer to check the validity of DT with ND filters, as described in Sect. 2.3.

\section{Conclusions}

In this study, we assess the effects of dead time on different products that are delivered by Brewer spectrophotometers, such as spectral UV irradiance, TOC and AOD. Moreover we assess the effectiveness of different methodologies to determine accurately the DT and the applied corrections to the measured radiation signals. The analysis of data from closure experiments and long-term measurements provides reliable estimates of the uncertainties associated with corrections applied for the dead time effects and reveals the importance for accurate determination of DT.

From a theoretical point of view, the application of either the extended or the non-extended approaches on Brewer measurements provides similar estimates of the DT. However, differences are revealed when the two approaches are applied for the correction of the signals. For signals higher than $\sim 2.5 \times 10^{6}$ counts s $^{-1}$ the non-extended approach results in more than $1 \%$ lower signals compared to those derived from the extended approach for the same value of the DT. As the signal decreases these differences are gradually eliminated. There are strong indications that the photon counting system of the Brewer is paralyzable and the currently used extended theory for the calculation of DT and the correction of the measurements provides accurate results. 
In the current Brewer algorithm, nine iterations of Eq. (12) are performed for the correction of the measured signals. We have found that the corrected signal converges already after five iterations, independently of intensity and the value of DT, for both the extended and the non-extended approaches. However, there is no reason to suggest reducing the number of iterations operationally since the time saved from the extra iterations is imperceptible.

The correction of the dark signal for the dead time effect was found unnecessary, as long as the level of the dark signal remains below $10^{4}$ counts $\mathrm{s}^{-1}$.

Further evaluation of the current algorithm for the determination of DT indicates that 10 iterations of Eqs. (9) and (10) are enough to give accurate results, as long as the signals at slit-mask positions 3 and 5 are of similar level (i.e., within a factor of 2); otherwise the number of iterations has to be increased. Fifty iterations were found enough to provide accurate results for signal ratios $\left(N_{3} / N_{5}\right)$ between $\sim 0.05$ and 20 . Increasing the signal and the number of cycles reduces the noise and the uncertainty of the final products. Specifically, as long as the signal level remains above $10^{6}$ counts s ${ }^{-1}$, measurements with 10 cycles are sufficient to keep the uncertainty of the calculated DT below $3 \%(\sim 1 \mathrm{~ns})$.

Measurements of the direct solar irradiance (which is usually stronger than the Brewer's internal standard lamp) provide more accurate estimates of DT with lower uncertainty. In order to achieve that, measurements should be performed at wavelength settings resulting in intensity ratio $\left(N_{3} / N_{7}\right)$ between 0.15 and 0.85 and signal at position 7 above $10^{6}$ counts $\mathrm{s}^{-1}$, while the number of iterations of Eqs. (9) and (10) has to be increased to 50. Since at some locations or seasons direct-Sun measurements might not be achievable for long periods, this method for estimating the DT should be used only complementarily to the standardlamp-based method. Occasionally, the standard-lamp-based method can lead to very noisy results so that the derived DT might not be the most suitable for the correction of the signals. In such cases, and when direct-Sun-based estimates of the DT are not available, the DT can be determined by optimizing the spectral transmittance of ND filters derived from measurements that are corrected with different DT values.

An independent check of the DT that provides the optimum correction to the measured signals has been achieved from short-term comparisons of the derived TOC with data from satellites. The specific methodology can be used alternatively or complementarily to the currently used methodologies. However, assessing the accuracy of DT by comparison with data from other instruments might not be safe because other parameters may interfere. Errors in parameters that are used to derive TOC (e.g., ETC, differential absorption coefficient) might lead to artificial nonlinearity which is subsequently balanced by the use of an incorrect DT. Analyzing TOC when ND filters change (Rodriguez-Franco et al., 2014) or irradiances as described in Sect. 2.3.4 can lead to safer conclusions.
Errors in UV irradiance spectral measurements are less than $2 \%$ even for $10 \mathrm{~ns}$ error in DT, as long as the signal remains below $2 \times 10^{6}$ counts $\mathrm{s}^{-1}$. However, the signal may be as high as 6-7 million counts $\mathrm{s}^{-1}$. As the incident irradiance is getting closer to this limit the errors are becoming more important. For such high signals, a 2 ns error in DT results into $2-4 \%$ error in irradiance, rising to $\sim 10 \%$ for $10 \mathrm{~ns}$ error. For the calculation of TOC, the uncertainties related to dead time effect are highly dependent on the shape of the instrument's spectral response and thus on the type of the instrument. For double-monochromator Brewers, the error in TOC does not exceed $2 \%$, even for 10 ns error in DT, while for single-monochromator Brewers the error may increase to $5 \%$. The tolerance of 2 ns suggested by Grajnar et al. (2008) has a negligible effect on TOC for double-monochromator Brewers and up to $1 \%$ for single-monochromator Brewers. Thus, according to Eq. (13), the $1 \sigma$ uncertainty in TOC from single-monochromator Brewers, solely due to errors in DT is $\sim 0.6 \%$. As the target for the total uncertainty in TOC measurements is $1 \%$ (Kerr et al., 1985), it is obvious that the suggested tolerance for DT has to be lowered. The effect of DT errors in the calculation of AOD is found to be less important compared to errors in UV irradiance and TOC.

Based on the results of this study we can summarize the following recommendations.

- The determination of DT from direct-Sun measurements should be used as complementary to the standard method with the internal standard lamp. Measurements for signals at the slit-mask positions 3 and 5 that differ by more than an order of magnitude should not be used to derive DT. To achieve uncertainty below $\sim 1 \mathrm{~ns}$ in the determination of DT, it is recommended that 10 or more cycles are used with the signal at position 7 above $10^{6}$ counts s $^{-1}$. The number of iterations of Eqs. (9) and (10) in the processing algorithm should be increased to 50 when the ratio $N_{3} / N_{7}$ is less than $\sim 0.3$.

- Regarding the TOC measurements from singlemonochromator Brewers, the tolerance of $2 \mathrm{~ns}$ in the DT error should be reduced to $1 \mathrm{~ns}$. Additionally, before a ND filter is set, the intensity at slit-mask positions 5 and 6 (316.8 and $320.1 \mathrm{~nm}$ ) should be checked in order to keep the maximum signal at all slits below the PMT safety threshold.

- Lowering the intensity threshold for both the singleand the double-monochromator Brewers is not recommended. Although it would reduce the uncertainties in TOC and AOD due to DT errors, it would also reduce the accuracy of the measurements, especially at slitmask positions 2 and 3 .

- In global spectral irradiance measurements the signal may reach $\sim 6 \times 10^{6}$ counts $\mathrm{s}^{-1}$, where the effect of errors in DT becomes very important. However, using dif- 
ferent ND filters to reduce this effect might result in increased uncertainties due to errors in the determination of the ND filters' transmittance (Redondas et al., 2011). Using a standard ND filter to reduce the responsivity of Brewers that measure such high signals would also reduce the accuracy of the measurements at shorter wavelengths. However, by using two different ND filters, one that is currently used for short wavelengths and one of stronger attenuation for longer wavelengths, the signal can be kept within the desired levels for the entire operational spectral range. The attenuation of the two ND filters can be implicitly taken into account during calibration. Furthermore, keeping the uncertainties in the calculation of DT below $1 \mathrm{~ns}$ and applying an appropriate post-correction to the measurements using the optimal DT can also reduce errors to less than $2 \%$.

This study has been accomplished in the framework of COST 1207 which aims at establishing a coherent network of European Brewer Spectrophotometer monitoring stations and, among other, to harmonize operations and achieve consistency in quality control and quality assurance. The results and suggestions of the present study will hopefully contribute to improve the quality of the Brewer products. Given that some Brewers are in operation since the early 1980s, more accurate correction for the dead time effect would lead to more accurate detection of trends in ozone, global UV irradiance and other products and to more reliable data that can be used for the validation of satellite products, as well as other applications in physical (Erickson III et al., 2015) and health (Lucas et al., 2015) sciences.

Acknowledgements. This article is based upon work from COST Action ES1207 "A European Brewer Network (EUBREWNET)", supported by COST (European Cooperation in Science and Technology). We would like to thank J. M. San Atanasio for providing data that, although not included, helped in deriving safer conclusions and P. Kiedron for his recommendations and discussions of various topics addressed in this study. We also acknowledge V. Savastiouk and the second, anonymous, reviewer for their constructive reviews and comments that helped improving the quality of this paper. In particular, we are indebted to V. Savastiouk for his detailed suggestions in addressing properly the calculation of the dead time when the Sun is used as radiation source instead of the Brewer internal standard lamp.

Edited by: A. Lambert

\section{References}

Bais, A. F., Zerefos, C. S., Meleti, C., Ziomas, I. C., and Tourpali, K.: Spectral measurements of solar UVB radiation and its relations to total ozone, $\mathrm{SO}_{2}$, and clouds, J. Geophys. Res., 98, 5199-5204, doi:10.1029/92jd02904, 1993.
Bais, A. F., Zerefos, C. S., and McElroy, C. T.: Solar UVB measurements with the double- and single-monochromator Brewer ozone spectrophotometers, Geophys. Res. Lett., 23, 833-836, doi:10.1029/96gl00842, 1996.

Bais, A. F., Kazantzidis, A., Kazadzis, S., Balis, D. S., Zerefos, C. S., and Meleti, C.: Deriving an effective aerosol single scattering albedo from spectral surface UV irradiance measurements, Atmos. Environ., 39, 1093-1102, doi:10.1016/j.atmosenv.2004.09.080, 2005.

Bernhard, G. and Seckmeyer, G.: Uncertainty of measurements of spectral solar UV irradiance, J. Geophys. Res.-Atmos., 104, 14321-14345, 1999.

Bernhard, G., Booth, C. R., Ehramjian, J. C., Stone, R., and Dutton, E. G.: Ultraviolet and visible radiation at Barrow, Alaska: Climatology and influencing factors on the basis of version $2 \mathrm{Na}$ tional Science Foundation network data, J. Geophys. Res., 112, D09101, doi:10.1029/2006jd007865, 2007.

Bhartia, P. K. and Wellemeyer, C.: TOMS-V8 total $\mathrm{O}_{3}$ algorithm, in OMI Algorithm Theoretical Basis Document, vol. II, OMI Ozone Products, edited by: Bhartia, P. K., NASA Goddard Space Flight Cent., Greenbelt, MD, available at: http://eospso.gsfc.nasa.gov/ atbd-category/49 (last access: 20 October 2015), 15-31, 2002.

Cappellani, F. and Bielli, A.: Correlation between $\mathrm{SO}_{2}$ and $\mathrm{NO}_{2}$ measured in an atmospheric column by a Brewer spectrophotometer and at ground-level by photochemical techniques, Environ. Monit. Assess., 35, 77-84, doi:10.1007/bf00633707, 1995.

Cede, A., Herman, J., Richter, A., Krotkov, N., and Burrows, J.: Measurements of nitrogen dioxide total column amounts using a Brewer double spectrophotometer in direct Sun mode, J. Geophys. Res., 111, D05304, doi:10.1029/2005jd006585, 2006.

Diémoz, H., Siani, A. M., Redondas, A., Savastiouk, V., McElroy, C. T., Navarro-Comas, M., and Hase, F.: Improved retrieval of nitrogen dioxide $\left(\mathrm{NO}_{2}\right)$ column densities by means of MKIV Brewer spectrophotometers, Atmos. Meas. Tech., 7, 4009-4022, doi:10.5194/amt-7-4009-2014, 2014.

Erickson III, D. J., Sulzberger, B., Zepp, R. G., and Austin, A. T.: Effects of stratospheric ozone depletion, solar UV radiation, and climate change on biogeochemical cycling: interactions and feedbacks, Photochem. Photobiol. Sci., 14, 127-148, doi:10.1039/c4pp90036g, 2015.

Farman, J. C., Gardiner, B. G., and Shanklin, J. D.: Large losses of total ozone in Antarctica reveal seasonal $\mathrm{ClO}_{x} / \mathrm{NO}_{x}$ interaction, Nature, 315, 207-210, 1985.

Fioletov, V. E., Griffioen, E., Kerr, J. B., Wardle, D. I., and Uchino, O.: Influence of volcanic sulfur dioxide on spectral UV irradiance as measured by Brewer Spectrophotometers, Geophys. Res. Lett., 25, 1665-1668, doi:10.1029/98gl51305, 1998.

Fioletov, V. E., Kerr, J. B., Wardle, D. I., Krotkov, N. A., and Herman, J. R.: Comparison of Brewer UV irradiance measurements with TOMS satellite retrievals, Opt. Eng., 41, 3051-3061, 2002.

Fioletov, V. E., Kerr, J. B., McElroy, C. T., Wardle, D. I., Savastiouk, V., and Grajnar, T. S.: The Brewer reference triad, Geophys. Res. Lett., 32, L20805, doi:10.1029/2005g1024244, 2005.

Fountoulakis, I. and Bais, A. F.: Brewer Operational Issues, Cost Action ES1207 EUBREWNET Open Congress/14th WMOGAW Brewer Users Group Meeting, State Meteorological Agency of Spain, Tenerife, Spain, 24-28 March 2014, 2014.

Garane, K., Bais, A. F., Kazadzis, S., Kazantzidis, A., and Meleti, C.: Monitoring of UV spectral irradiance at Thessaloniki 
(1990-2005): data re-evaluation and quality control, Ann. Geophys., 24, 3215-3228, doi:10.5194/angeo-24-3215-2006, 2006.

Glandorf, M., Arola, A., Bais, A., and Seckmeyer, G.: Possibilities to detect trends in spectral UV irradiance, Theor. Appl. Climatol., 81, 33-44, doi:10.1007/s00704-004-0109-9, 2005.

Grajnar, T., Savastiouk, V., and McElroy, T.: Brewer Standard Operative Procedure (Draft) http://www.io3.ca/Download/Brewer SOP_DRAFT.pdf (last access: 20 October 2015), 2008.

Gröbner, J. and Meleti, C.: Aerosol optical depth in the UVB and visible wavelength range from Brewer spectrophotometer direct irradiance measurements: 1991-2002, J. Geophys. Res.-Atmos., 109, D09202, doi:10.1029/2003jd004409, 2004.

Gröbner, J., Blumthaler, M., Kazadzis, S., Bais, A., Webb, A., Schreder, J., Seckmeyer, G., and Rembges, D.: Quality assurance of spectral solar UV measurements: results from 25 UV monitoring sites in Europe, 2002 to 2004, Metrologia, 43, S66-S71, doi:10.1088/0026-1394/43/2/S14, 2006.

Hasinoff, S.: Photon, poisson noise, in: Computer Vision, edited by: Ikeuchi, K., Springer, New York, 608-610, doi:10.1007/978-0387-31439-6, 2014.

Haus, D. J.: Optical Sensors: Basics and Applications, Wiley-VCH Verlag GmbH \& Co. KGaA, Wenheim, Germany, 2010.

Kapusta, P., Wahl, M., and Erdmann, R. (Eds.): Advanced Photon Counting: Applications, Methods, Instrumentation, Vol. 15, Springer, Zürich, Switzerland, 370 pp. 2015.

Karppinen, T., Redondas, A., García, R. D., Lakkala, K., McElroy, C. T., and Kyrö, E.: Compensating for the effects of stray light in single-monochromator brewer spectrophotometer ozone retrieval, Atmos. Ocean, 53, 66-73, doi:10.1080/07055900.2013.871499, 2014.

Kazadzis, S., Bais, A., Amiridis, V., Balis, D., Meleti, C., Kouremeti, N., Zerefos, C. S., Rapsomanikis, S., Petrakakis, M., Kelesis, A., Tzoumaka, P., and Kelektsoglou, K.: Nine years of UV aerosol optical depth measurements at Thessaloniki, Greece, Atmos. Chem. Phys., 7, 2091-2101, doi:10.5194/acp-7-20912007, 2007.

Kazadzis, S., Bais, A., Kouremeti, N., Gerasopoulos, E., Garane, K., Blumthaler, M., Schallhart, B., and Cede, A.: Direct spectral measurements with a Brewer spectroradiometer: absolute calibration and aerosol optical depth retrieval, Appl. Opt., 44, 16811690, 2005.

Kerr, J.: The Brewer Spectrophotometer, in: UV Radiation in Global Climate Change, edited by: Gao, W., Slusser, J., and Schmoldt, D., Springer, Berlin, Heidelberg, 160-191, 2010.

Kerr, J. B. and McElroy, C. T.: Evidence for large upward trends of ultraviolet-B radiation linked to ozone depletion, Science, 262, 1032-1034, doi:10.1126/science.262.5136.1032, 1993.

Kerr, J. B., McElroy, C. T., and Olafson, R. A.: Measurements of ozone with the Brewer spectrophotometer, in: Proceedings of the Quadrennial International Ozone Symposium, edited by: London, J., Natl. Cent. Atmos. Res., Boulder, CO, 74-79, 1981.

Kerr, J. B., Evans, W. F. J., and Asbridge, I. A.: Recalibration of Dobson field spectrophotometers with a travelling brewer spectrophotometer standard, in: Atmospheric Ozone, edited by: Zerefos, C. S. and Ghazi, A., Springer, Utrecht, the Netherlands, 381386, 1985.

Kiedron, P.: Counts and Noise, NOAA-EPA Brewer Network, available at: http://www.esrl.noaa.gov/gmd/grad/neubrew/docs/ CountsAndNoise.pdf (last access: 20 October 2015), 2007.
Kimlin, M. G., Taylor, T. E., Wilson, A., and Meltzer, R. S.: Techniques for monitoring and maintaining the performance of Brewer MkIV spectrophotometers, Opt. Eng., 44, 041008041011, doi:10.1117/1.1885471, 2005.

Kipp \& Zonen: Brewer MKIII Spectrophotometer Operators Manual, Kipp \& Zonen Inc., Delft, the Netherlands, 2008.

Lakkala, K., Arola, A., Heikkilä, A., Kaurola, J., Koskela, T., Kyrö, E., Lindfors, A., Meinander, O., Tanskanen, A., Gröbner, J., and Hülsen, G.: Quality assurance of the Brewer spectral UV measurements in Finland, Atmos. Chem. Phys., 8, 33693383, doi:10.5194/acp-8-3369-2008, 2008.

Lucas, R. M., Norval, M., Neale, R. E., Young, A. R., de Gruijl, F. R., Takizawa, Y., and van der Leun, J. C.: The consequences for human health of stratospheric ozone depletion in association with other environmental factors, Photochem. Photobiol. Sci., 14, 53-87, doi:10.1039/c4pp90033b, 2015.

Meinander, O., Josefsson, W., Kaurola, J., Koskela, T., and Lakkala, K.: Spike detection and correction in Brewer spectroradiometer ultraviolet spectra, Opt. Eng., 42, 1812-1819, 2003.

Meleti, C. and Cappellani, F.: Measurements of aerosol optical depth at Ispra: analysis of the correlation with UV-B, UV-A, and total solar irradiance, J. Geophys. Res., 105, 4971-4978, doi:10.1029/1999jd900459, 2000.

Redondas, A. M. and Rodriguez, J. J.: Regional Brewer Calibration Center - Europe CEOS campaigns: Instrumental Findings, Quadrennial Ozone Symposium 2012 (QOS 2012), ID:6166, Toronto, Canada, 27-31 August 2012, 2012.

Redondas, A. M., Carreño V., Afonso, S., Rodriguez Franco, J. J., Almansa, F., and Sierra, M.: Regional Brewer Calibration Center - Europe, 2011, Brewer Workshop Beijing, 13 September 2011, 2011.

Redondas, A. M., Vilaplana, J. M., Rodríguez, J. J., McElroy, T., Savastiouk, V., Hülsen, G., Lamb, K., Stanek, M., Taoufik, Z., Lopez-Bartolomé, M., Rimmer, J., and Lee, C.: C.E.O.S. RBCCE Huelva intercomparison results, Quadrennial Ozone Symposium 2012 (QOS 2012), ID:6161, Toronto, Canada, 27-31 August 2012, 2012.

Rodriguez Franco, J. J., Redondas, A. M., Sierra, M., and Carreño, V.: "Intercomparison campaigns: Instrumental findings", 2014, Cost Action ES1207 Eubrewnet Open Congress/14th WMO-GAW Brewer Users Group Meeting, State Meteorological Agency of Spain, Tenerife, Spain, 24-28 March 2014, 2014.

Savastiouk, V.: Improvements to the direct-sun ozone observations taken with the Brewer spectrophotometer, PhD Thesis, York University, Toronto, 2005.

Schätzel, K.: Dead time correction of photon correlation functions, Appl. Phys. B, 41, 95-102, doi:10.1007/bf00702660, 1986.

SCI-TEC Instruments Inc.: Brewer MkII Spectrophotometer, Operator's Manual, SCI-TEC Instruments Inc., Saskatoon, Saskatchewan, 1999.

Sellitto, P., Sarra, A. D., and Siani, A. M.: An improved algorithm for the determination of aerosol optical depth in the ultraviolet spectral range from Brewer spectrophotometer observations, J. Opt. A-Pure Appl. Op., 8, 849-855, doi:10.1088/14644258/8/10/005, 2006.

Thomason, L. W., Herman, B. M., and Reagan, J. A.: The effect of atmospheric attenuators with structured vertical distributions on air mass determinations and Langley plot 
analyses, J. Atmos. Sci., 40, 1851-1854, doi:10.1175/15200469(1983)040<1851:teoaaw>2.0.co;2, 1983.

Weatherhead, E. C., Reinsel, G. C., Tiao, G. C., Meng, X.-L., Choi, D., Cheang, W.-K., Keller, T., DeLuisi, J., Wuebbles, D. J., Kerr, J. B., Miller, A. J., Oltmans, S. J., and Frederick, J. E.: Factors affecting the detection of trends: statistical considerations and applications to environmental data, J. Geophys. Res., 103, 17149-17161, doi:10.1029/98jd00995, 1998.

Wenig, M. O., Cede, A. M., Bucsela, E. J., Celarier, E. A., Boersma, K. F., Veefkind, J. P., Brinksma, E. J., Gleason, J. F., and Herman, J. R.: Validation of OMI tropospheric $\mathrm{NO}_{2}$ column densities using direct-Sun mode Brewer measurements at NASA Goddard Space Flight Center, J. Geophys. Res., 113, D16S45, doi:10.1029/2007jd008988, 2008.
Yu, D. F. and Fessler, J. A.: Mean and variance of single photon counting with deadtime, Phys. Med. Biol., 45, 2043-2056, 2000.

Zerefos, C. S.: Long-term ozone and UV variations at Thessaloniki, Greece, Phys. Chem. Earth A/B/C, 27, 455-460, doi:10.1016/S1474-7065(02)00026-8, 2002. 